\title{
The insect pathogenic bacterium Xenorhabdus innexi has attenuated virulence in multiple insect model hosts yet encodes a potent mosquitocidal toxin
}

II-Hwan Kim 1,2, Sudarshan K. Aryal ${ }^{3}$, Dariush T. Aghai ${ }^{4}$, Ángel M. Casanova-Torres ${ }^{4}$, Kai Hillman ${ }^{4}$, Michael P. Kozuch ${ }^{4}$, Erin J. Mans ${ }^{4,5}$, Terra J. Mauer ${ }^{4,5}$, Jean-Claude Ogier ${ }^{6}$, Jerald C. Ensign ${ }^{4}$, Sophie Gaudriault ${ }^{6}$, Walter G. Goodman ${ }^{1}$, Heidi Goodrich-Blair ${ }^{4,5^{*}}$ (i) and Adler R. Dillman ${ }^{3 *}$

\begin{abstract}
Background: Xenorhabdus innexi is a bacterial symbiont of Steinernema scapterisci nematodes, which is a cricketspecialist parasite and together the nematode and bacteria infect and kill crickets. Curiously, $X$. innexi expresses a potent extracellular mosquitocidal toxin activity in culture supernatants. We sequenced a draft genome of $X$. innexi and compared it to the genomes of related pathogens to elucidate the nature of specialization.
\end{abstract}

Results: Using green fluorescent protein-expressing $X$. innexi we confirm previous reports using culture-dependent techniques that $X$. innexi colonizes its nematode host at low levels ( 3-8 cells per nematode), relative to other Xenorhabdus-Steinernema associations. We found that compared to the well-characterized entomopathogenic nematode symbiont $X$. nematophila, $X$. innexi fails to suppress the insect phenoloxidase immune pathway and is attenuated for virulence and reproduction in the Lepidoptera Galleria mellonella and Manduca sexta, as well as the dipteran Drosophila melanogaster. To assess if, compared to other Xenorhabdus spp., X. innexi has a reduced capacity to synthesize virulence determinants, we obtained and analyzed a draft genome sequence. We found no evidence for several hallmarks of Xenorhabdus spp. toxicity, including Tc and Mcf toxins. Similar to other Xenorhabdus genomes, we found numerous loci predicted to encode non-ribosomal peptide/polyketide synthetases. Anti-SMASH predictions of these loci revealed one, related to the $f c l$ locus that encodes fabclavines and $z m n$ locus that encodes zeamines, as a likely candidate to encode the $X$. innexi mosquitocidal toxin biosynthetic machinery, which we designated XIt. In support of this hypothesis, two mutants each with an insertion in an XIt biosynthesis gene cluster lacked the mosquitocidal compound based on HPLC/MS analysis and neither produced toxin to the levels of the wild type parent.

Conclusions: The $X$. innexi genome will be a valuable resource in identifying loci encoding new metabolites of interest, but also in future comparative studies of nematode-bacterial symbiosis and niche partitioning among bacterial pathogens.

Keywords: Virulence, Toxin, Symbiosis, Insect, Immunity, NRPS/PKS, Mosquito, Lipopeptide

* Correspondence: hgblair@utk.edu; adlerd@ucr.edu

${ }^{4}$ Department of Bacteriology, University of Wisconsin-Madison, Madison, WI,

USA

${ }^{3}$ Department of Nematology, University of California, Riverside, CA, USA

Full list of author information is available at the end of the article

(c) The Author(s). 2017 Open Access This article is distributed under the terms of the Creative Commons Attribution 4.0 International License (http://creativecommons.org/licenses/by/4.0/, which permits unrestricted use, distribution, and reproduction in any medium, provided you give appropriate credit to the original author(s) and the source, provide a link to the Creative Commons license, and indicate if changes were made. The Creative Commons Public Domain Dedication waiver (http://creativecommons.org/publicdomain/zero/1.0/) applies to the data made available in this article, unless otherwise stated. 


\section{Background}

Nematodes in the genus Steinernema associate with Xenorhabdus bacteria in a mutually beneficial relationship that allows the pair to utilize insect hosts as a reproductive niche. Steinernema nematodes have a soildwelling stage, known as the infective juvenile (IJ) that carries Xenorhabdus bacteria into insect prey that will be killed and used for nutrients that support reproduction. Progeny IJs then emerge from the spent insect cadaver, carrying their Xenorhabdus partner, to begin the cycle again. In general, the bacterial symbionts promote nematode fitness by helping kill insect hosts and by contributing to the degradation and protection of the host cadaver from competitors and predators [1]. Because they can be pathogenic to insects when injected without their nematode host, Xenorhabdus bacteria and their genes are being exploited for use in agricultural settings to help control important crop pests. For example, certain $X$. nematophila genes can confer resistance to insect pests when expressed transgenically in plants $[2,3]$. The potential for insecticidal and natural product discovery has helped spur the sequencing and analysis of multiple Xenorhabdus spp. genomes [4-7].

Recently, renewed attention has been placed on the biology of Steinernema scapterisci, a nematode first isolated by G.C. Smart and K.B. Nguyen in 1985 from mole crickets found in Uruguay [8-11]. The bacterial symbiont found within these nematodes was later established as a new species, Xenorhabdus innexi [12]. The relationship between $S$. scapterisci and $X$. innexi appears to be specific; six species of Xenorhabdus have been tested in previous studies and only $X$. innexi colonizes the infective juvenile (IJ) stage of S. scapterisci [13].

S. scapterisci is closely related to the well-studied steinernematid nematode $S$. carpocapsae [14-17], but has distinctive characteristics that make it useful for comparative purposes, including its specialization for cricket hosts $[9,11,18,19]$. While both $S$. carpocapsae and $S$. scapterisci caused death when injected into $A$. domesticus (house cricket), only $S$. scapterisci reproduced to high levels (S. carpocapsae produced $\sim 7 \%$ the infective juvenile progeny relative to $S$. scapterisci), and fewer (16\%) $S$. scapterisci were melanized compared to $S$. carpocapsae (92\%), indicating S. scapterisci either does not induce an immune response in $A$. domesticus or is resistant to it [19]. A common feature of host-seeking parasitic nematodes is the activation of the IJ stage upon exposure to host tissue [11, 20, 21]. For entomopathogenic nematode (EPN) IJs, this activation process includes morphological changes of the mouth, pharynx, and anterior gut, as well as release of the symbiotic bacteria into the host and secretion of a variety of proteins that are thought to be involved in parasitism $[22,23]$. A recent study demonstrated that more than $70 \%$ of S. scapterisci IJs are activated within $18 \mathrm{~h}$ of exposure to cricket tissue while fewer than
$30 \%$ of the IJs are activated when exposed to G. mellonella waxworm tissue for the same period of time [11], supporting the notion that $S$. scapterisci is a cricket specialist.

The specialization of $S$. scapterisci and its symbiont for crickets is in contrast to their attenuated effectiveness against other insects. When injected into Popillia japonica (Japanese beetle), S. carpocapsae can kill and reproduce, but S. scapterisci cannot. Further, although conflicting reports occur in the literature, compared to other Steinernema species, S. scaptersci appears to have reduced capacity to kill or reproduce in Galleria mellonella $[13,18,24]$, which is a standard bait host. It has been suggested that the low virulence of $S$. scapterisci in wax worms is due to the relatively low virulence of its associated symbiont $X$. innexi $[10,25]$, as well as negative impacts from non-Xenorhabdus microbes that can be associated with S. scapterisci IJs [10].

Generally, Steinernema bacterial symbionts are thought to benefit their hosts by contributing to insect death and degradation. Using aposymbiotic $S$. scapterisci nematodes and cultured $X$. innexi symbionts, Bonifassi et al. determined that neither was pathogenic towards G. mellonella individually, but were when combined [10]. This indicates that both partners are necessary to kill this insect, in contrast to $S$. carpocapsae and $X$. nematophila each of which can kill insects without the other (see, for example [26, 27]). Later studies demonstrated that $S$. scapterisci could survive, parasitize, and reproduce aposymbiotically in G. mellonella, but with reduced overall fitness [24], and that the impact of different Xenorhabdus species on S. scapterisci fitness is directly correlated with their phylogenetic relatedness to $X$. innexi [13]. Generally, these studies support the idea that $X$. innexi specifically facilitates the establishment of S. scapterisci nematode infection and production of progeny IJs in insect hosts. However, Sicard et al. noted that $S$. scapterisci fared better in the absence of its symbiont than did the other nematode species examined, and that it was colonized by fewer bacterial symbionts $(\sim 0.07 \mathrm{CFU} / \mathrm{IJ}$ average, relative to 43.8 CFU/IJ for $X$. nematophila) as measured using a crushing and plating method [24]. Taken together, these reports suggest that $S$. scapterisci is trending toward decreased dependence of the nematode on its bacterial symbiont.

Although the findings reviewed above hinted that $X$. innexi may be less virulent, at least toward some insect hosts, than other Xenorhabdus species, an activity-screening approach revealed that it does secrete a peptide with insecticidal activity effective against the larvae of several mosquito species in the Aedes, Anopheles, and Culex genera [28]. Recent work has indicated the active compound is a lipopeptide, 
dubbed Xenorhabdus lipoprotein toxin (Xlt) that can create pores in the apical surface of mosquito larval anterior midgut cells [29].

The experiments presented here were geared toward directly testing the nematode colonization and insect virulence properties of $X$. innexi, to provide further insights into the evolution of different symbiotic relationships among Steinernema-Xenorhabdus pairings. Further, we sought to identify distinctive virulence determinants that may be encoded by $X$. innexi relative to other Xenorhabdus species, predicted based on the specialization of the $X$. innexi-S. scapterisci symbiotic pair for crickets, and the production by $X$. innexi of a mosquitocidal toxin. To pursue these goals we established a laboratory model of S. scapterisci-X. innexiinsect symbiosis. We assessed $X$. innexi virulence in several model insects, applied genetic tools to facilitate monitoring its presence and gene function, and used draft genome sequencing and analysis to explore its virulence potential.

\section{Results}

S. scapterisci IJ receptacles are colonized by few $X$. innexi cells

To assess the colonization levels of $X$. innexi in $S$. scapterisci nematodes, we added axenic nematodes (see Methods) to lawns of two $X$. innexi strains, one (HGB1681) isolated from S. scapterisci nematodes provided by Prof. Grover Smart (FL) and the other isolated from the S. scapterisci nematodes being used in this study (provided by Becker Underwood Inc.) (Table 1). IJs emerging from in vitro cultures such as those described above were surface sterilized and subjected to a grinding assay to calculate average colony-forming units (CFU) of bacteria per IJ. Both tested X. innexi strains colonized S. scapterisci at $\sim 7 \mathrm{CFU} / \mathrm{IJ}$ (Table 2) and colonies were confirmed to be $X$. innexi based on distinctive phenotypic traits (catalase negative, characteristic brown color, and distinctive odor). No colonies grew from homogenates of axenic nematodes cultivated on $X$. nematophila, confirming the previous finding that $X$. nematophila does not colonize S. scapterisci nematodes (Table 2) [24].

The low colonization level we detected could be due to low frequency of colonization (few nematodes in the population are colonized) or low levels of colonization (the majority of nematodes are colonized by very few bacteria) or a combination of these phenotypes. To address this question, we generated $X$. innexi strains expressing green fluorescent protein (GFP) (Table 1) to facilitate their visualization within IJ receptacles (Fig. 1) [30]. As with non-GFP expressing strains, progeny IJs emerging from lawns of GFP-expressing $X$. innexi were colonized by an average of approximately 7-10 CFU/IJ, as determined by grinding assays (Table 2). Visualization by fluorescence microscopy revealed GFP-expressing bacterial cell colonization of the S. scapterisci IJs (Fig. 1b). S. carpocapsae and S. scapterisci had visible green-fluorescent bacteria at frequencies of $94.8 \pm 0.007$ and $92.7 \pm 0.016$, respectively (mean \pm SD of three biological replicates of each nematode species). Like other Xenorhabdus spp., including $X$. nematophila, $X$. innexi localized to the receptacle region of the intestine posterior to the basal bulb. However, $X$. innexi appears distinct in that only a few cells (1-5 cells) were visible within the receptacles of individual colonized IJs (Fig. 1b), in contrast to the large number of $X$. nematophila occupying this region in $S$. carpocapsae nematodes (Fig. 1a). These observations support the quantitative data acquired by grinding, and indicate that $X$. innexi colonizes S. scapterisci IJs at a high frequency, but at very low levels compared to $X$. nematophila colonization of $S$. carpocapsae (typically $\sim 40 \mathrm{CFU} / \mathrm{IJ}$ using this method) [31]. We next examined the growth characteristics of $X$. innexi in laboratory medium, compared to $X$. nematophila and $X$. bovienii, the symbiont of $S$. jollieti, two Xenorhabdus bacteria for which complete genomes exist [6]. We found that in LB medium, $X$. innexi displayed a longer lag, a significantly slower growth rate (Additional file 1), and a lower final $\mathrm{OD}_{600}$ compared to $X$. bovienii and $X$. nematophila (Fig. 1c).

\section{$X$. innexi is avirulent at ecologically relevant doses}

Given that an individual $S$. scapterisci nematode would inoculate an insect host with few cells of its $X$. innexi symbiont (Fig. 1) [24], we next assessed the contribution of $X$. innexi to the nematode-symbiont complex by injecting quantified doses into several potential insect hosts and the model insect Drosophila melanogaster. We compared this to the virulence of $X$. nematophila, the well-characterized bacterial symbiont of $S$. carpocapsae.

Similar to previous studies [32, 33], we found that $X$. nematophila is highly toxic to G. mellonella waxworm larvae, rapidly killing these insects even at low doses (Fig. 2a). X. nematophila quickly grew in waxworm larvae, reaching over 1 million colony-forming units (CFUs) in less than $24 \mathrm{~h}$, regardless of the inoculating dose (Fig. 2b). We found similar results in adult D. melanogaster, where $X$. nematophila rapidly killed the adults and grew to over 1 million CFUs in less than $18 \mathrm{~h}$ (Fig. 2c-d; Additional file 2). In contrast to X. nematophila, $X$. innexi was nearly avirulent when injected into fruit fly adults (Fig. 2e). We found that all but the highest dose we tried, 100,000 CFUs, proved to have little to no effect on fruit fly survival. We plotted the growth of the bacteria in infected flies over time and found that $D$. melanogaster adults are highly resistant to $X$. innexi (Fig. 2f). The flies reduced bacterial 
Table 1 Strains and plasmids used in this study

\begin{tabular}{|c|c|c|}
\hline & Relevant characteristics & Source/Reference \\
\hline \multicolumn{3}{|l|}{ Strain } \\
\hline HGB800 & $\begin{array}{l}\text { Xenorhabdus nematophila isolated from } \\
\text { Steinernema carpocapsae All nematodes }\end{array}$ & ATCC19061 \\
\hline HGB1053 & Xenorhabdus bovienii SS-2004 & [119] \\
\hline HGB1681 & $\begin{array}{l}\text { Xenorhabdus innexi isolated from } \\
\text { Steinernema scapterisci nematodes from } \\
\text { Grover Smart. Also called Xenorhabdus } \\
\text { MT, deposited to ATCC in } 2005 \text {. }\end{array}$ & $\begin{array}{l}\text { G.C. Smart Jr. University of } \\
\text { Florida; ATCC PTA-6826 }\end{array}$ \\
\hline HGB1997 & $\begin{array}{l}\text { Xenorhabdus innexi isolated in } 2013 \text { from } \\
\text { Steinernema scapterisci nematodes } \\
\text { obtained from Becker-Underwood }\end{array}$ & This study \\
\hline HGB2171 & HGB1681 attTn7/Tn7-GFP (from pURR25) & This study \\
\hline HGB2172 & HGB1997 attTn7/Tn7-GFP (from pURR25) & This study \\
\hline HGB283 & Escherichia coli S17-1 lambda pir pUX-BF13 & [107] \\
\hline HGB1262 & Escherichia coli BW29427 pURR25, mini Tn7KS-GFP & B. Lies and D. Newman [108] \\
\hline TOP10 & E. coli strain for general cloning & Thermo \\
\hline \multicolumn{3}{|l|}{ Plasmids } \\
\hline pBluescript II SK (-) & General cloning & Stratagene \\
\hline pKanWOR & $\begin{array}{l}\text { pBluescript KS+ with Km cassette (1 kb) } \\
\text { in BamHI site }\end{array}$ & H. Goodrich-Blair \\
\hline pCR-Blunt II-TOPO & General cloning vector, Kanr & Thermo \\
\hline pBlueXIS1_460109Up & XIS1_460109Up inserted in pBluescript SK- & This study \\
\hline pBlueXIS1_460109UpDn & $\begin{array}{l}\text { XIS1_460109Dn inserted in } \\
\text { pBlueXIS1_460109Up }\end{array}$ & This study \\
\hline pBlueXIS1_460109UpKanDn & $\begin{array}{l}\text { Kan cassette from pKanWOR inserted in } \\
\text { pBlueXIS1_460109UpDn }\end{array}$ & This study \\
\hline pBlueXIS1_460115Up & XIS1_460115Up inserted in pBluescript SK- & This study \\
\hline pBlueXIS1_460115UpDn & XIS1_460115Dn inserted in pBlueXIS1_460115Up & This study \\
\hline pBlueXIS1_460115UpKanDn & $\begin{array}{l}\text { Kan cassette from pKanWOR inserted in } \\
\text { pBlueXIS1_460115UpDn }\end{array}$ & This study \\
\hline pKR100 & oriR6K suicide vector, $\mathrm{Cmr}$ & H. Goodrich-Blair \\
\hline pKRXIS1_460109 & XIS1_460109UpKanDn inserted in pKR100 & This study \\
\hline pKRXIS1_460115 & XIS1_460115UpKanDn inserted in pKR100 & This study \\
\hline
\end{tabular}

growth and eventually cleared the bacteria from the system, even when given an initial dose of 10,000 CFUs (Fig. 2f). When we injected 100,000 CFUs, the bacterial cells were able to grow and kill the flies quickly, but this dose would require more than

Table 2 X. innexi colonization of S. scapterisci nematodes

\begin{tabular}{lll}
\hline Strain & Relevant Characteristics & Avg. CFU/IJ $\pm \mathrm{SE}^{a}$ \\
\hline HGB1681 & X. innexi (Smart) & $6.1 \pm 1.1$ \\
HGB1997 & $X$. innexi (BD) & $7.9 \pm 1.4$ \\
HGB2171 & $X$. innexi (Smart) GFP & $6.4 \pm 1.4$ \\
HGB2172 & $X$. innexi (BD) GFP & $6.7 \pm 1.0$ \\
HGB800 & $X$. nematophila & $<0.005$ \\
\hline
\end{tabular}

${ }^{a}$ Average colony forming units (CFU) per infective juvenile (IJ) \pm standard error (SE) from four independent experiments
14,000 nematode IJs to initiate infection and therefore is not ecologically relevant (Fig. 1) [24]. X. innexi was also avirulent in waxworm larvae, except when injected at 100,000 CFUs (Fig. 2g). In Manduca sexta larvae, an inoculum of $1000 \mathrm{CFU}$ was sufficient for $X$. nematophila to cause death of $50 \%$ of insects by $48 \mathrm{~h}$ post-injection, while $X$. innexi only killed $10 \%$ of insects toward the end of the experiment $(5 \mathrm{~d}$ postinjection) (Fig. 2h). The attenuated virulence of $X$. innexi in these various insects supports the idea that the $S$. scapterisci-X. innexi complex has a specialized host range. Further, we used the growth data from these experiments to calculate in vivo growth rates in $D$. melanogaster, which, similar to in vitro growth rates, are lower for $X$. innexi than for $X$. nematophila (Additional file 1). 


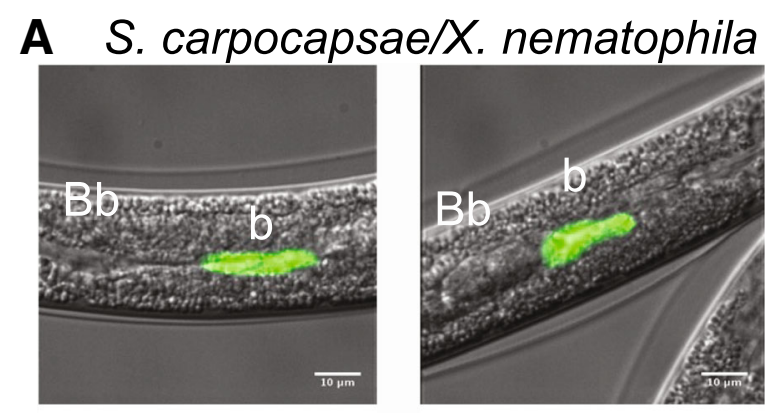

\section{B S. scapterisci/X. innexi}

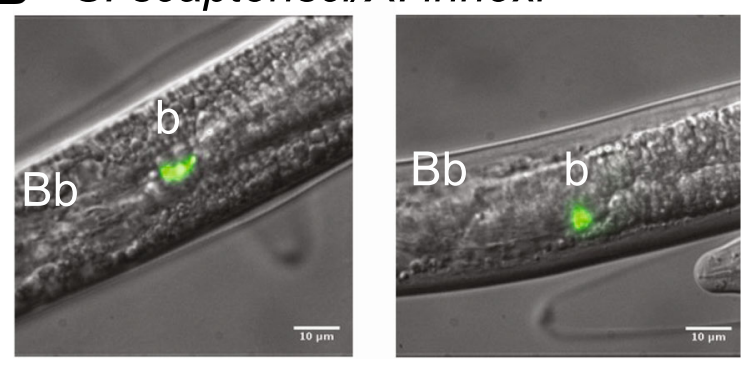

C Growth in LB

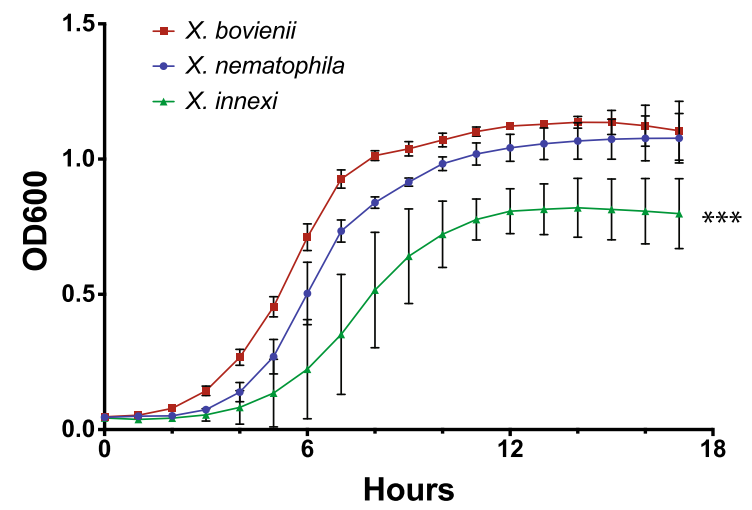

Fig. $1 X$. innexi nematode colonization levels and in vitro growth rate are lower than other Xenorhabdus species. a S. carpocapsae or (b) S. scapterisci nematodes were reared on lawns of their respective symbionts, $X$. nematophila and $X$. innexi, engineered to express the green fluorescent protein. Approximately 100 infective juveniles of each nematode species emerging from these lawns were examined by fluorescence microscopy to visualize bacterial colonization of the nematode receptacle and two representative images are shown for each nematode. All colonized S. scapterisci nematodes had smaller regions of green fluorescence in the receptacle than did colonized S. carpocapsae. When individual bacterial cells could be resolved only 2-3 cells were apparent within S. scapterisci nematodes. Both nematode species were colonized at similar frequencies ( 92-97\%). Bb: basal bulb; b: bacteria. c $X$. bovienii (red squares), $X$. nematophila (blue circles), and $X$. innexi (green triangles) bacteria were subcultured into LB medium and monitored for growth based on optical density $\left(\mathrm{OD}_{600)} \times\right.$. innexi displayed a longer lag time, slower growth rate, and lower final cell densities than the other two bacterial species,.$X$. innexi density became significantly different from that of $X$. nematophila and $X$ bovienii after $6 \mathrm{~h}$ and remained significantly different for the remainder of the experiment $(* * *$ : $P<0.002,2$-way ANOVA at each time point with Tukey's multiple comparisons test), and the overall growth curve was significantly different using Extra sum-of-squares $F$ text $(P=0.0001)$

\section{$X$. innexi supernatant does not suppress the Manduca sexta phenoloxidase cascade}

A common activity associated with Xenorhabdus bacteria is the ability to suppress aspects of insect immunity, including the phenoloxidase (PO) system. $\mathrm{PO}$ is activated by the cleavage of proPO, which occurs as a result of a serine protease cascade [34]. Several metabolites secreted by $X$. nematophila such as rhabduscin can inhibit the activation of PO [35-37]. To determine if $X$. innexi also secretes immunosuppressive metabolites we isolated cell-free supernatant from it and X. nematophila as a control and assessed their abilities to inhibit the activation of $\mathrm{PO}$ when incubated with plasma extracted from $M$. sexta insects (Fig. 3). We found that as expected, $X$. nematophila produces heat-tolerant factor(s) that can reduce PO activation to $30 \%$ of control reactions. In contrast, $X$. innexi supernatants do not inhibit the activation of $\mathrm{PO}$, indicating that when grown to stationary phase in laboratory culture this bacterium does not secrete immunosuppressive factors at levels sufficient for detection in this assay.

\section{The $X$. innexi genome has a reduced complement of genes predicted to encode virulence determinants, compared to those of other Xenorhabdus spp}

We have presented data that $X$. innexi is attenuated for virulence in several insect models and for the secretion of immunosuppressive factors. These data and previous publications support a model that $S$. scapterisci is less reliant than other EPNs on its symbiont for fitness. However, $X$. innexi does contribute to $S$. scapterisci success in some insect hosts $[10,13,24]$ and also produces several factors of interest, including a mosquitocidal toxin [28]. We predicted that the genome of $X$. innexi might reveal a reduction in the canonical virulence determinants associated with Xenorhabdus and related species, while also potentially encoding novel virulence factors that contribute to its specialization for virulence in certain insect hosts.

To further investigate these ideas, we produced a draft genome sequence for X. innexi strain HGB1681 (Table 3) (Accession for the whole genome shotgun sequencing project: FTLG00000000.1). The XIS1 draft genome comprises 69 scaffolds (LT699767-LT699835) and 246 contigs (FTLG01000001-FTLG01000246). In total, the genome is similar in size $(4,574,778 \mathrm{bp}), \mathrm{GC}$ content $(43.68 \%)$, and coding potential (4418 CDS) and density (83\%) to the complete genomes of $X$. nematophila and $X$. bovienii (Table 3) [6]. Due to the draft status of the sequenced genome, only one copy of $16 \mathrm{~S}$ rRNA, one copy of $23 \mathrm{~S}$ rRNA and two copies of 5S rRNA were successfully assembled while the completed genomes of both $X$. nematophila and $X$. bovienii have multiple copies of each rRNA gene. Since lower copy numbers of rRNA operons is associated with 


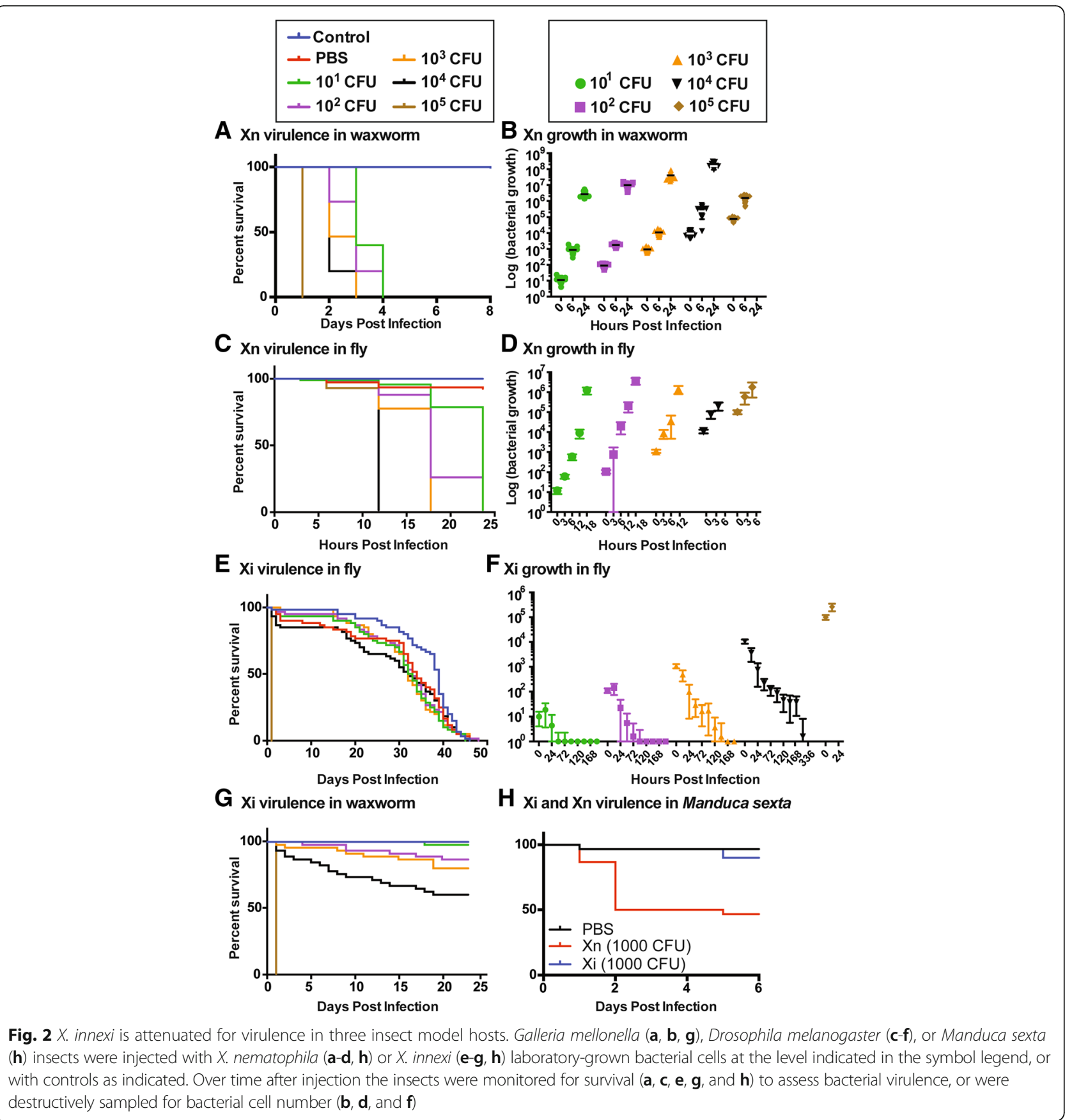

lengthened lag phase and growth rate [38-40], phenotypes we have observed for $X$. innexi, it is possible that $X$. innexi does encode fewer rRNA gene copies, but this conclusion awaits further investigation. The draft genome of $X$. innexi encodes the same number (79) of tRNAs as do the complete genomes of $X$. nematophila and X. bovienii.

To investigate the virulence coding potential of the $X$. innexi genome, CDS protein sequences were analyzed using similarity to known virulence factors and conserved protein domains (Table 4, see Methods for details) [41]. In addition to these direct searches, we used the MicroScope Gene Phyloprofile tool [42] to identify sets of genes specifically absent in $X$. innexi genome (Additional file 3). We used loci present in the completely sequenced genome of the virulent strain $X$. nematophila (ATCC 19061) and identified those with homologs in the genomes of the virulent strains $X$. bovienii SS-2004 and $X$. doucetiae FRM16 $[6,7]$, but without homologs in the $X$. innexi HGB1681 genome.

Consistent with the reduction of virulence potential and absence of PO inhibition, the draft genome $X$. innexi lacked, or had a reduced complement of virulence 


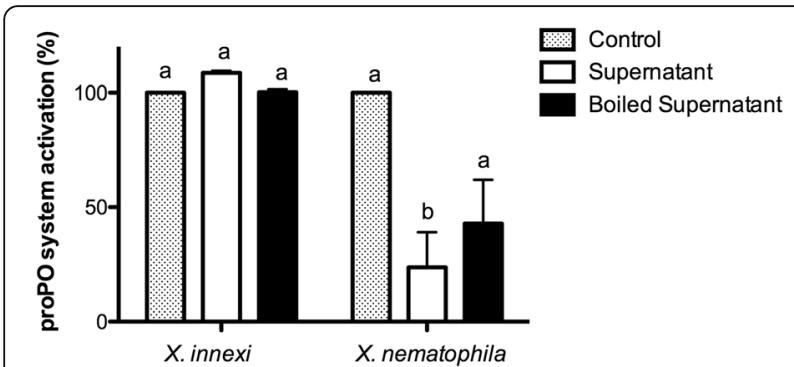

Fig. $3 X$. innexi supernatant does not suppress prophenoloxidase activation. Percent proPO system activation \pm SEM in hemolymph incubated with control medium (dotted bars) or cell-free supernatant from $X$. innexi or $X$. nematophila that was either untreated (white bars) or boiled for $10 \mathrm{~min}$. at $95^{\circ} \mathrm{C}$ (black bars). Different letters indicate significant difference ( $p<0.05$, one-way ANOVA Friedman test followed by Dunn's post test) was observed between strains when compared for proPO inhibition

factors typical of other Xenorhabdus genomes. For example, $X$. innexi does not encode Tc (or associated chitinases), Mcf, XaxAB, entire Rtx (see below), or Pir toxins [6,43-46] or rhabduscin-encoding genes [37] (Table 4; Additional file 3).

\section{In silico analysis of select $X$. innexi secretion systems and effectors}

Bacteria encode numerous types of secretion systems, many of which allow delivery of virulence factors to the host environment and cells. As with other Xenorhabdus bacterial genomes [6], the genome of $X$. innexi lacks a Type III secretion system (T3SS) (determined using $S$. enterica T3S as a model; Additional file 4). Another class of secreted molecules that are often found in pathogens that lack T3SS is the MARTX (Multifunctional Autoprocessing Repeats-in-Toxin Toxins). These polymorphic toxins are very large and comprise an $\mathrm{N}$-terminal region with conserved $\mathrm{A}$ and $\mathrm{B}$ repeats that appear necessary for delivery of the toxin into host cells, an effector

Table 3 Draft genome statistics

\begin{tabular}{llll}
\hline & $\begin{array}{l}\text { X. innexi } \\
\text { HGB1681 }\end{array}$ & $\begin{array}{l}\text { X. nematophila } \\
\text { ATCC 19061 }\end{array}$ & $\begin{array}{l}\text { X. bovienii } \\
\text { SS-2004 }\end{array}$ \\
\hline Size of chromosome (bp) & $4,575,778$ & $4,432,590$ & $4,225,498$ \\
G + C content, \% & 43.68 & 44.15 & 44.97 \\
Coding sequences & 4418 & 4648 & 4406 \\
Number of scaffolds & 69 & 1 & 1 \\
Number of contigs & 246 & 1 & 1 \\
Average CDS length (bp) & 885.8 & 850.81 & 849.48 \\
Average intergenic length (bp) & 179.85 & 163.62 & 158.03 \\
Protein coding density \% & 82.93 & 82.65 & 84.07 \\
rRNAs & 4 & 29 & 29 \\
tRNAs & 79 & 79 & 83 \\
\hline
\end{tabular}

Table 4 Numbers of $X$. nematophila and $X$. innexi genes encoding known virulence factors

\begin{tabular}{lll}
\hline Gene family & X. innexi & X. nematophila \\
& HGB1681 & ATCC 19061 \\
\hline Chitinases & 0 & 2 \\
HIP57 (GroEL) & 1 & 3 \\
MARTX & $3^{\mathrm{a}}$ & 1 \\
Mcf & 0 & 1 \\
Pir toxins & 0 & 2 \\
PrtA & 1 & 1 \\
Rhabduscin & 0 & 3 \\
TC toxins (A) & 0 & $6^{\mathrm{a}}$ \\
TC toxins (B) & 0 & 3 \\
TC toxins (C) & $1^{\mathrm{a}}$ & 3 \\
TPS-Fha & $2^{\mathrm{a}}$ & 0 \\
TPS-Hemolysin & $2^{\mathrm{a}}$ & 1 \\
Xenocin & 0 & 1 \\
\hline
\end{tabular}

indicates at least one fragment

domain region containing multiple modules with hostmodulating functions, a CPD domain that processes the effector domains once in the host cell, and a C-terminal repeat domain necessary for secretion out of the bacterial cell through a Type 1 secretion system encoded by the $r t x E D B$ operon and the unlinked tolC gene [47, 48] (Fig. 4).

Published literature has established that the $X$. nematophila and $X$. bovienii genomes each contain one complete MARTX-encoding gene, predicted to encode proteins of 4970 aa and 4716 aa respectively, each with canonical A repeats (A1-A10; A11-A14), B repeats (B1-38; B39-41) and $C$ repeats $(\mathrm{C} 1-2 ; \mathrm{C} 3-15)$, and a $\mathrm{CPD}$ domain. Both also contain the effector domains DUF1, RID, and MCF, but they are distinct in that $X$. nematophila includes a PMT C1/C2 (now known as RRSP) domain $[49,50]$. while that of $X$. bovienii encodes an $\mathrm{ABH}$ domain, both immediately following their respective RID domains [51, 52]. Consistent with the genomic context of other organisms, the MARTX-encoding genes of $X$. nematophila and $X$. bovienii are encoded adjacent to those predicted to encode Rtx activating and secretion functions.

The $X$. innexi genome contains 4 contigs with regions that have similarity to MARTX-encoding genes, based on a BLASTp search with XNC1_1381 (Fig. 4). In the assembly, only one gene (XIS1_650005) encodes a full suite of $\mathrm{A}, \mathrm{B}$, and $\mathrm{C}$ repeats and the effector domains. However, based on alignment with the $X$. nematophila and $X$. bovienii MARTX proteins this protein lacks A repeats 4 through 8 (of 14) (Fig. 4 and Additional file 5). In addition to XIS1_650005, we identified another five regions with one or more MARTX protein-encoding domains. Of these, two (XiS1v1_640001 and XIS1_650001) are predicted to encode an A domain region that, like 


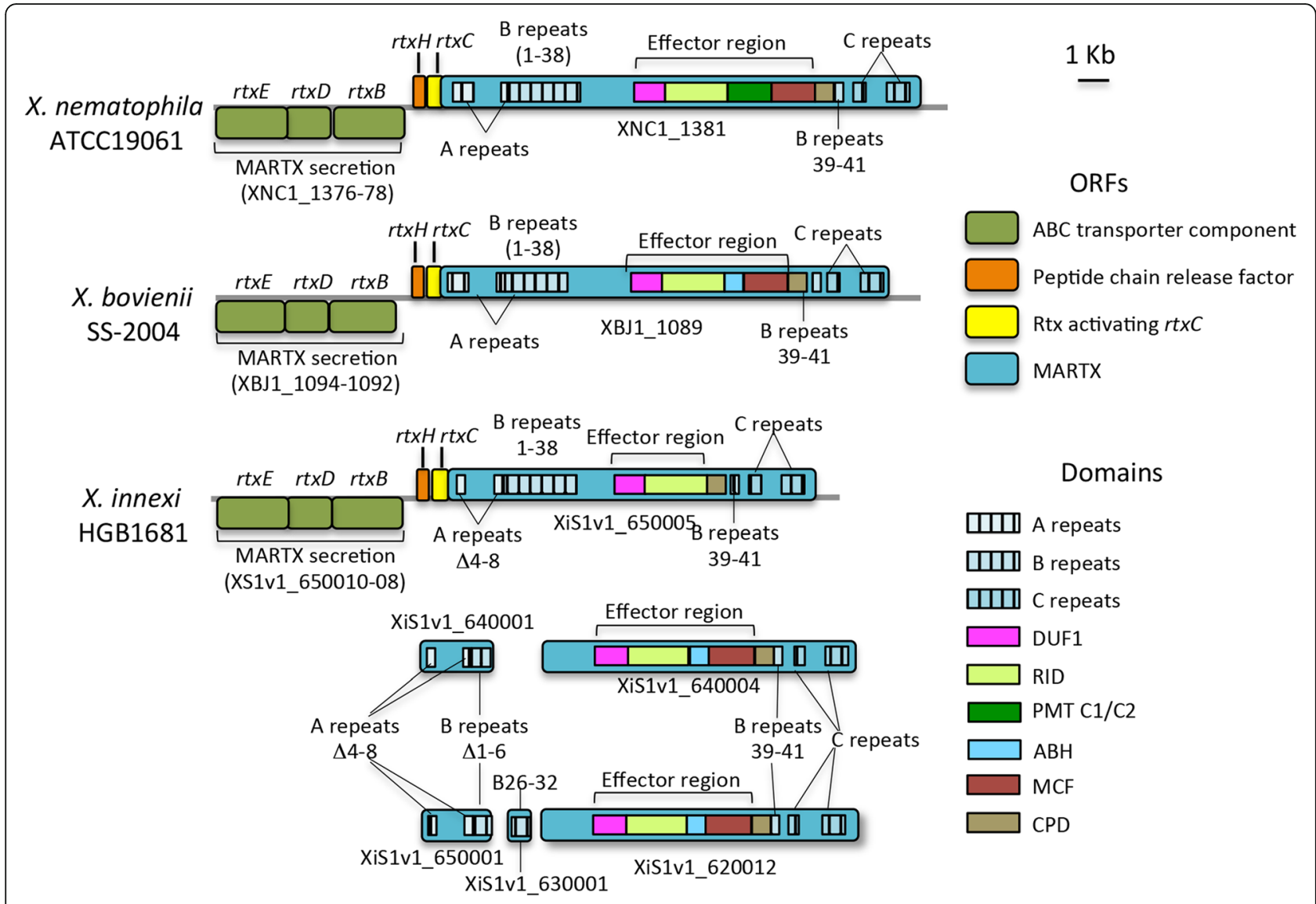

Fig. 4 Comparison of MARTX loci in the $X$. nematophila, $X$. bovienii and $X$. innexi genomes. Schematic representations of loci containing MARTX protein domains (A, B, and C repeat regions and an effector domain region) in X. nematophila ATCC19061, X. bovienii SS-2004, and X. innexi HGB1681. Taller boxes represent open reading frames (locus tags indicated below each), color-coded according to the predicted product, and shorter boxes indicate MARTX subdomains (A, B, and C repeats; indicated with hatching, and effector domains, indicated with color-coding). In functional MARTX proteins the A domain has 14 repeats, the two B domains have 38 (1-38) and 3 (39-41) repeats respectively, and the $C$ domain has 15 repeats. In $X$. innexi missing repeats from within these domains are noted with the $\square$ symbol

XIS1_650005, lack repeats 4 through 8, as well as a truncated B domain region (extending up to repeat 16 of 38 ) that lack repeats B1-B6 (Fig. 4 and Additional file 5). Additional B repeats (corresponding to $\sim$ B24 through B33) are found encoded by XIS1_630001. Finally, XIS1_640004 and XIS1_620012 both encode B repeats (38-41) and an effector domain region with the same composition as that of X. bovienii (Fig. 4 and Additional file 5). In sum, consistent with the attenuated virulence of $X$. innexi, the genome appears not to encode a complete MARTX protein (since internal repeats appear to be missing from the A domain of XIS1_650005). It will be of interest to determine the functional significance of the absence of these repeats, assuming that the missing repeats are verified and not due to assembly issues.

Another secretion system with implications for virulence are the two-partner secretion (TPS) systems (also known as Type 5 or autotransporters), which encode both the toxin (e.g. hemolysin) and its transport system
(Tables 4 and 5) [53]. In these systems one protein forms a beta-barrel pore that facilitates translocation of an exoprotein across the outer membrane. Typically, the betabarrel protein and the exoprotein are encoded adjacent to each other. A conserved feature of these systems is the TPS domain encoded in the N-terminal 250 aa of the A exoprotein, which is necessary for translocation and contains a conserved NPNL-35aa-NPNGI motif. Generally, this region is conserved across types of secreted exoproteins, while the remaining portions of the protein are distinct. Previous phylogenetic analyses of whole TpsA sequences [6] revealed that Tps proteins are divided into three clusters. The first cluster contains CdiA exoproteins, which are involved in the contact-dependent inhibition systems, playing important roles in inter-strain competition and self/nonself discrimination. CDI systems are mainly distributed among pathogenic Gram-negative bacteria [54-57], and recently described in the entomopathogenic bacterium Xenorhabdus doucetiae FRM16 [58]. 
Table $5 X$. innexi two partner secretion pathway loci

\begin{tabular}{|c|c|c|c|c|}
\hline $\mathrm{XIS1}$ & Gene & Length (aa) & Predicted Function & TPS cluster or relevant features \\
\hline 1110028 & $x h / B_{x i}$ & 558 & Beta-barrel & Cluster II (hemolysin) \\
\hline 1110029 & $x h / A_{x i}$ & 1468 & Exoprotein & Cluster II (hemolysin), TPS motif \\
\hline 1600025 & $x h \mid B 2_{x i}$ & 558 & Beta-barrel & Cluster II (hemolysin) \\
\hline 1600026 & $\begin{array}{l}x h / A 2_{x i} \\
\text { (part 1) }\end{array}$ & 656 & Exoprotein fragment & Cluster II (hemolysin), TPS motif \\
\hline 1600027 & $x h \mid A 2_{x i}$ (part 2) & 801 & Exoprotein fragment & Cluster II (hemolysin) \\
\hline 680062 & $c d i B_{x i}$ & 569 & Beta-barrel & Cluster I (Cdi) \\
\hline 680061 & $c d i A_{x i}$ & 4029 & Exoprotein & Cluster I (Cdi), TPS motif and VENN domain \\
\hline 680060 & $c d i l_{x i}$ & 4029 & Immunity protein & Cluster I (Cdi), putative $c d i I_{x i}$ \\
\hline 260016 & cdiB-like $_{x i}$ & 571 & Beta-barrel & Cluster I (Cdi) \\
\hline 260017 & $\begin{array}{l}\text { cdiA-like } \\
\text { (part 1) }\end{array}$ & 1157 & $\begin{array}{l}\text { Exoprotein } \\
\text { fragment }\end{array}$ & Cluster I (Cdi), TPS motif, lacks VENN motif \\
\hline 270001 & $\begin{array}{l}\text { cdiA-like } \\
\text { (part 2) }\end{array}$ & 180 & Exoprotein fragment & $\begin{array}{l}\text { Cluster I (Cdi), lacks TPS motif and VENN } \\
\text { domain, contains beta barrel region, }\end{array}$ \\
\hline 280001 & $\begin{array}{l}\text { cdiA-like } \\
\text { (part 3) }\end{array}$ & 4062 & $\begin{array}{l}\text { Exoprotein } \\
\text { fragment }\end{array}$ & $\begin{array}{l}\text { Cluster I (Cdi), lacks TPS motif, starts with } \\
\text { the beta barrel region, includes VENN domain }\end{array}$ \\
\hline 1500009 & $\operatorname{tps} B_{x i}$ & 566 & Beta-barrel & Cluster III (DUF637 domain) \\
\hline 1500008 & $\operatorname{tps} A_{x i}$ & 1907 & Exoprotein & $\begin{array}{l}\text { Cluster III (DUF637 domain), TPS motif and } \\
\text { DUF637 domain }\end{array}$ \\
\hline 1500007 & $\left.\operatorname{tps}\right|_{x i}$ & 110 & unknown & potential immunity protein \\
\hline
\end{tabular}

The second cluster is comprised of active hemolysins, such as PhlA from Photorhabdus luminescens and XhlA from $X$. nematophila $[59,60]$. A third cluster contains TpsA proteins with unknown functions, which are characterized by the presence of a DUF637 domain.

In the draft $X$. innexi genome we identified a total of five genes predicted to encode proteins with an $\mathrm{N}$ terminal TPS domain including conserved NPNL and NPNGI domains (Table 5). The genomic contexts of these suggest five independent loci encoding Tps systems. XIS1_1110029 and XIS1_1600026 genes encode proteins with TPS domains that belong to the hemolysin phylogenetic cluster (Fig. 5; Additional file 6). The XIS1_1110029-encoding protein displays 67\% identity over its entire length (1468 aa) to the $X$. nematophila XhlA hemolysin $\left(\mathrm{XhlA}_{\mathrm{xn}}\right)$ [59] and was therefore named $\mathrm{XhlA}_{\mathrm{xi}} \cdot x h l A_{x i}$ is adjacent to a homolog of $x h l B$ predicted to encode the beta-barrel protein component of the TPS system. The genomic locus $x h l B A_{x i}$ is syntenic with that of $x h l B A_{x n}$, and includes genes predicted to encode a Type VI secretion system (T6SS). XIS1_1600026 is contiguous to XIS1_1600027 and they encode putative proteins that have respectively $52 \%$ identity with the $\mathrm{N}$ terminal region of $\mathrm{XhlA}_{\mathrm{xn}}$ and $32 \%$ identity with the Cterminal region of $\mathrm{XhlA}_{\mathrm{xn}}$ These two genes are adjacent to another homolog of $x h l B$ (XIS1_1600025). Overall, it appears that $X$. innexi encodes a second $x h l B A_{x i}$ locus, with $x h l A_{x i}$ truncated in two parts (XIS1_16000276/ XIS1_1600027).
XIS1_680,061 and XIS1_260,017 encode proteins with TPS domains that belong to the Cdi phylogenetic cluster (Fig. 5). The XIS1_680,061-encoding protein displays identity with functionally characterized CdiA proteins $(36 \%$ identity with the $X$. doucetiae FRM16 CdiA and 34\% identity with the E. coli EC93 CdiA) and has a VENN domain, which usually separates the conserved $\mathrm{N}$-terminus from the variable C-terminus in many CdiA proteins [61]. Moreover, the adjacent genes XIS1_680062 and XIS1_680060 encode a CdiB ortholog and a potential immunity protein Cdil (based on location of the gene and the small size of the encoded-protein), respectively. We therefore hypothesize that this locus is a cdiBAI locus. XIS1_ 260017, XIS1_270001 and XIS1_280001 are on three separate contigs but are contiguous in the assembly of the $X$. innexi genome. They each display partial similarities with sub-regions of CdiA proteins. These three $c d i A$-like genes are adjacent to a $\mathrm{CdiB}$ ortholog XIS1_ 260016 (63\% identity with CdiB of $X$. doucetiae FRM16), which suggest the presence of a second cdi locus, which has been highly shuffled.

The fifth tps genomic locus we identified includes XIS1_150008, encoding a 1907 aa protein with a TPSdomain and a DUF637 domain, placing it in the third phylogenetic cluster (Fig. 5), for which no function is described to date. XIS1_150009 encodes a TpsB ortholog. Interestingly, XIS1_150007 displays features of immunity genes due to its location and its small size although the 

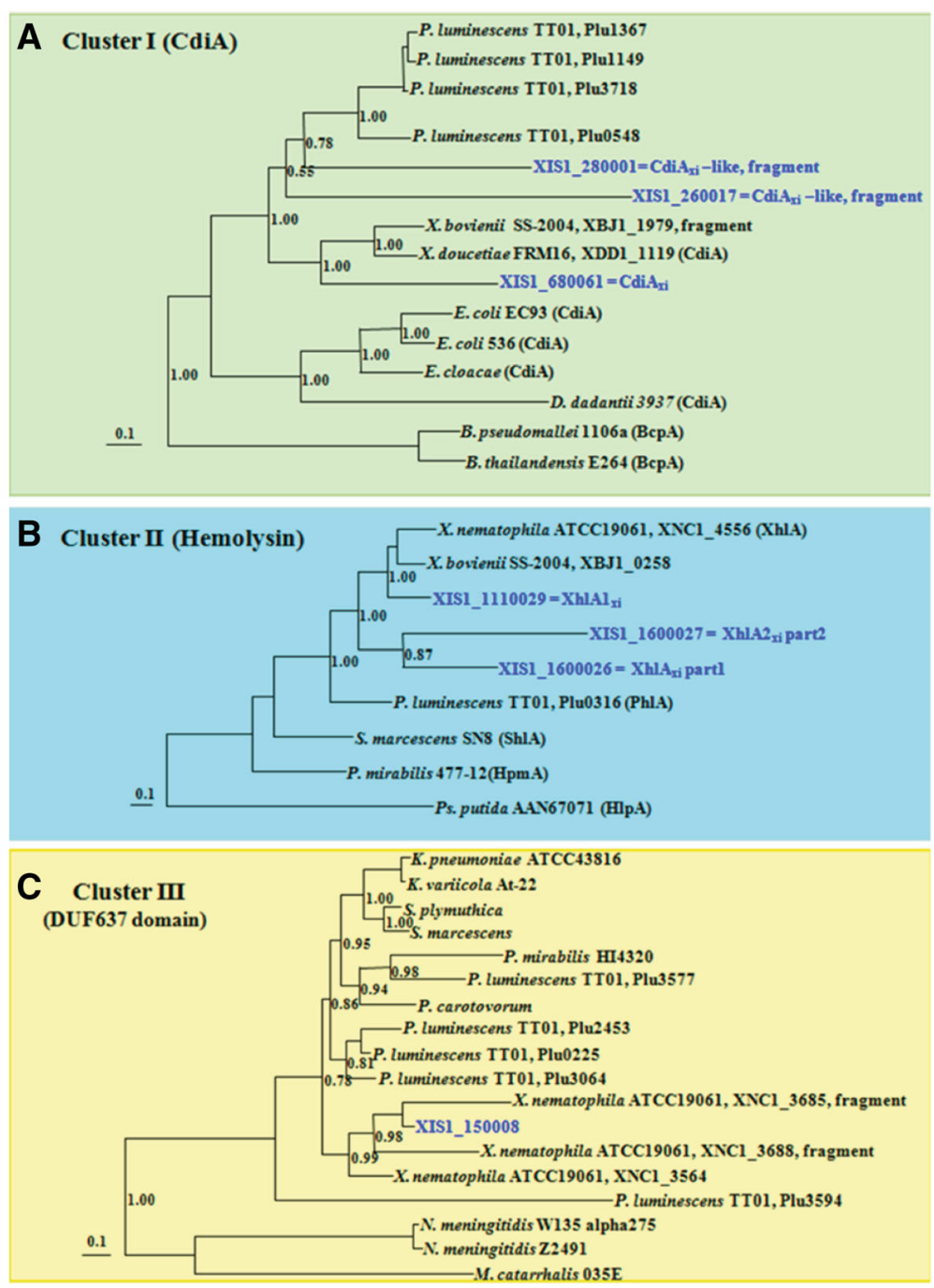

Fig. 5 Phylogenetic analysis of putative TpsA proteins of $X$. innexi. For each family of TpsA proteins, a phylogenetic tree was built by the maximum likelihood (ML) method using the LG substitution model. Branch support values, estimated by the aLRT (SH-like) method, are indicated at the nodes. The branch length scale bar below the phylogenetic tree reflects the number of amino-acid substitutions per site. TpsA proteins fall into three clusters: a Cluster I containing CdiA exoproteins, which are involved in contact-dependent inhibition systems, b Cluster II containing hemolysins and (c) Cluster III containing TpsA proteins with unknown functions, which are all characterized by the presence of DUF637 domain. TpsA are identified by the name of the bacterial strain in each cluster and the label number in the Photorhabdus and Xenorhabdus genera. The X. innexi TpsA proteins are indicated in blue with the label number of their encoding gene. Previous functionally characterized TpsA are named in parentheses. Accession numbers of the sequences are indicated in Additional file 6

tpsA gene does not fall in the Cdi phylogenetic cluster (Table 5).

In summary, the $X$. innexii genome displays tps clusters in each of the three phylogenetic clusters, which sets it apart from other Xenorhabdus genomes. For instance, in the genome of the highly virulent Xenorhabdus nematophila ATCC19061 strain, only hemolysin and DUF637 domain clusters are represented (Fig. 5; Additional file 6).

Another class of secretion systems that can be involved in virulence is the T6SS. These are bacterial nanomachines comprising 13 conserved structural proteins, which deliver toxic effectors into eukaryotic or prokaryotic organisms in a one-step firing mechanism [62]. T6SSs often are associated with roles in virulence and inter-bacterial competition, providing a selective advantage against competitors [63]. To analyze the T6SS content in the draft genome of $X$. innexi, we used a combination of the Magnifying Genomes server (MaGe) and NCBI Conserved Domain Database and identified three T6SS clusters, T6SS-1,2, and 3 (named in order of their appearance in the draft genome) (Fig. 6a, Additional file 7).

T6SS-1 appears to be incomplete, as it lacks the tssJ, tss G, and $c l p V$ components. Although $\mathrm{ClpV}$ is dispensable for some T6SSs, Tss] and TssG are required [62] suggesting the 


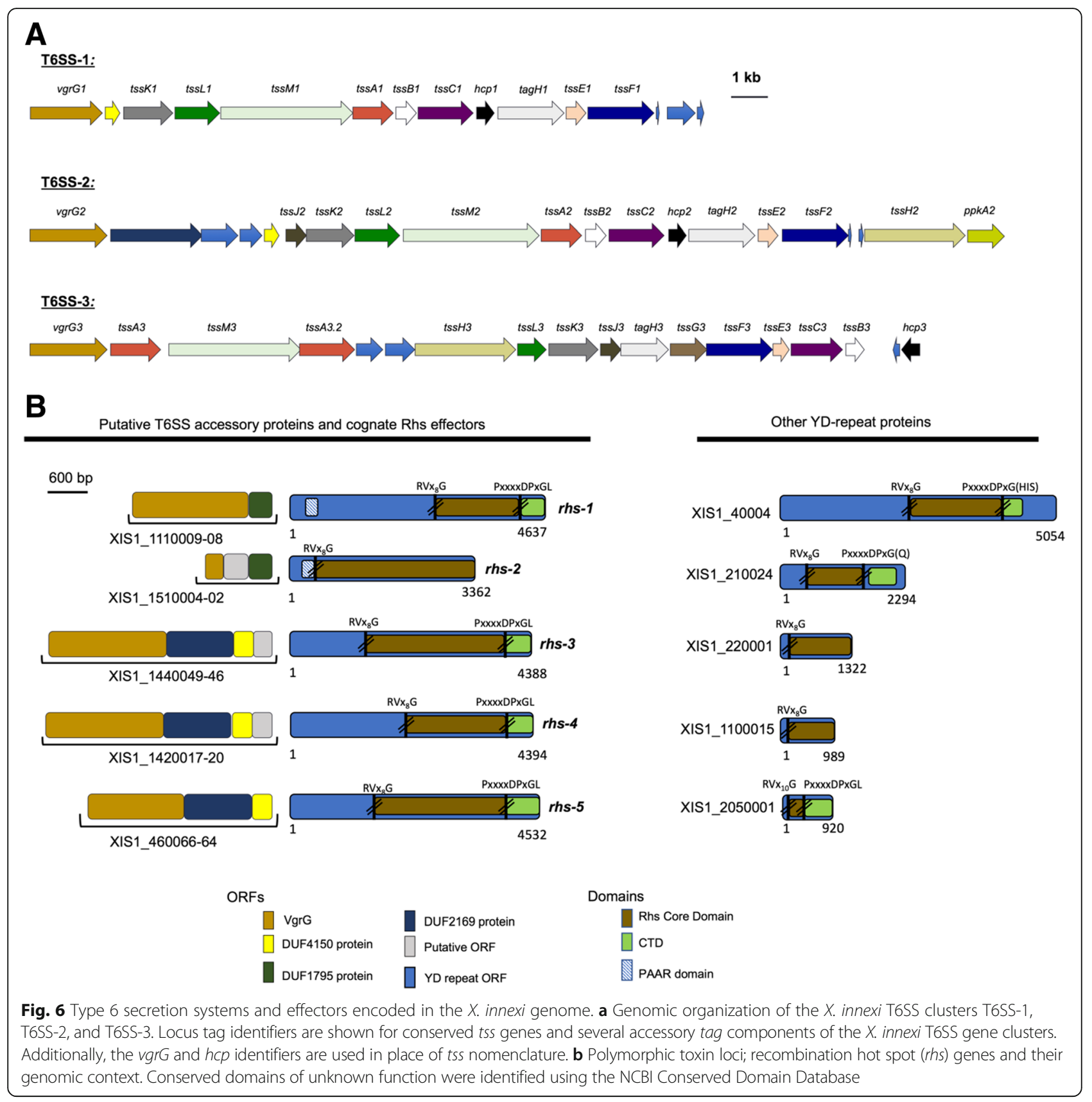

$X$. innexi T6SS-1 system may not be functional. The T6SS-2 cluster lacks tss G, but contains all other core components as well as potential effector-immunity (E-I) protein pairs. Additionally, T6SS-2 contains both tagH, a forkhead-associated domain-containing protein, and $p p k A$, a transmembrane threonine kinase. TagH and PpkA are components of the threonine phosphorylation pathway (TPP), a post-translational regulatory mechanism for T6SS activity [64]. The T6SS-3 cluster appears complete and includes a duplication of the baseplate protein, $t s s A$, and a potential E-I protein pair. Genes encoding putative T6SS E-I pairs can be found clustered with the T6SS structural genes or scattered about the genome, often linked to a T6SS chaperone. One such group of T6SS effectors is the polymorphic toxins, Rhs proteins.

Rhs proteins containing PAAR domains have been reported as T6SS-dependent antibacterial effectors that mediate both intra- and inter-species competition [65]. Rhs proteins, in human pathogens such as Pseudomonas aeruginosa and Enterobacter cloacae, mediate bacterial competition under in vitro conditions. For these pathogens, Rhs proteins may play an important role in virulence by establishing a suitable niche for survival during infection of the host [66]. Genes encoding known or 
putative T6S effectors, including Rhs proteins, are often found near $\operatorname{vgrG}$ genes and require the cognate $\mathrm{Vgr}$ for T6S secretion [67]. X. innexi strain HGB1681 encodes ten YD-repeat (PF05593) proteins, five of which are putative Rhs proteins based on the presence of characteristic YD-repeats, a rhs core domain flanked by conserved motifs, and a variable C-terminal 'tip' [68] (Fig. 6b). These five genes can be further categorized into two groups based on their genomic context. Two genes, $X i_{-} r h s-1$ and $X i_{-} r h s-2$ encode an N-terminal PAAR motif (PF05488), though $X i_{-} r h s-2$ is annotated as a truncated ORF, missing its $\mathrm{C}$-terminal-encoding domain. The other three (Xi_rhs-3 through rhs-5) lack the PAAR domain but are encoded next to small open reading frames with a PAAR-like domain, DUF4150/PF13665. Furthermore, the Xi_rhs-1 and Xi_rhs-2 are encoded downstream of a DUF1795-containing protein and putative $\operatorname{vgr} G$ gene, both of which were necessary for Rhs protein translocation in Serratia marcescens [69]. The other three rhs genes are also encoded downstream of putative $\operatorname{vgrG}$ genes. The genomic contexts of these three $r h s$ genes are distinct from those of $r h s-1$ and $r h s-2$ in that these gene clusters also encode DUF2169 and DUF4150 domain-containing proteins, which in Agrobacterium tumefaciens are demonstrated accessory proteins required for secretion of their cognate T6SS toxin [67].

The highly variable C-terminal domains (CTDs) of Rhs proteins contain the toxic effector activity. An analysis of the CTDs of $X$. innexi Rhs-family proteins (except $X i \_r h s-2$ which lacks a CTD) revealed no recognizable CTD function in rhs-3, -4 , and -5 . In contrast rhs-1 contains PF14437, a MafB19 deaminase domain [70]. This domain occurs in the CTDs of several classes of polymorphic toxins, including the recently recognized Neisseria MafB toxins, and the Rhs protein putative toxin E1IMF [70]. While our data demonstrate that in several insect hosts, $X$. innexi displays attenuated virulence relative to other Xenorhabdus spp. it remains an associate of $S$. scapterisci nematodes (Fig. 1, Table 2), and successfully reproduces within crickets, where it may encounter competing microbes (Additional file 8). Together with the T6SS, the Rhs family proteins encoded by $X$. innexi may play a role in any one of these activities.

The $X$. innexi genome includes numerous loci predicted to encode non-ribosomal peptide and polyketide synthetases

Non-ribosomal peptide synthetase (NRPS) and polyketide synthetase (PKS) clusters encode large molecular weight complexes responsible for the synthesis of small molecules (natural products) with diverse activities, including toxicity against target organisms [71]. To begin to assess the ability of $X$. innexi to produce such compounds we computationally screened for clusters predicted to encode NRPS, PKS, or hybrids. Our initial screening identified one PKS, 12 NRPS and three NRPSPKS hybrid gene clusters (Table 6). The hybrid genes were

Table 6 NPRS, PKS, and NPRS-PKS hybrid clusters in the X. innexi genome

\begin{tabular}{llll}
\hline Location & Size $(\mathrm{bp})$ & Type & Number of A or AT domains $^{\mathrm{a}}$ \\
\hline XIS1_130014 & 5139 & PKS $^{\mathrm{b}}$ & 1 AT domain \\
XIS1_250010 & 13,755 & NRPS $^{c}$ & 6 A domains \\
XIS1_40005 - XIS1_60002 & 21,138 & NPRS & 4 A domains \\
XIS1_170001 - XIS1_190004 & 21,111 & NPRS & 6 A domains \\
XIS1_370002 - XIS1_370004 & 15,468 & NPRS & 3 A domains \\
XIS1_390007 - XIS1_400001 & 15,519 & NPRS & 5 A domains \\
XIS1_450016 & 2997 & NRPS & 1 A domain \\
XIS1_460014 & 7323 & NPRS & 2 A domains \\
XIS1_460105 - XIS1_460116 & 44,193 & Hybrid & 6 A domains and 2 AT domains \\
XIS1_480023 - XIS1_480027 & 23,055 & Hybrid & 3 A domains and 1 AT domain \\
XIS1_600036 & 3060 & NRPS & 1 A domain \\
XIS1_660020 - XIS1_660029 & 21,609 & Hybrid & 3 A domains and 1 AT domain \\
XIS1_1050018 - XIS1_1050019 & 3366 & NRPS & 1 A domain \\
XIS1_1690009 - XIS1_1690010 & 23,319 & NRPS & 7 A domains \\
XIS1_1700078 & 11,811 & NRPS & 3 A domains \\
XIS1_1750018 - XIS1_1750021 & 44,826 & NRPS & 13 A domains
\end{tabular}

${ }^{a}$ A domain; Adenylation domain, AT domain; Acyltransferase domain predicted by antiSMASH

bPKS; Polyketide synthase

'NRPS; Non-ribosomal peptide synthetase

${ }^{\mathrm{d}}$ Hybrid; NRPS-PKS hybrid gene 
further examined by analyzing their amino acid sequences through AntiSMASH or Conserved Domain searches to identify NRPS and PKS domains and to confirm the number of adenylation (A) and acyltransferase (AT) domains, which are responsible for selection and loading of amino acids or carboxylic acids, respectively for incorporation into the product (Table 6).

\section{Identification of the XIt-encoding NRPS/PKS hybrid gene cluster}

$X$. innexi secretes a small lipopeptide named Xlt with toxicity toward mosquitoes [28, 29]. Previous structural data suggested that Xlt is a cyclic lipopeptide composed of six amino acids and two fatty acids [28] and we hypothesized that it may be synthesized by a hybrid NRPS/PKS cluster [72]. Based on this hypothesis, we predicted that the locus would encode six A- and two AT-domains respectively. Among the three identified hybrid genes in $X$. innexi genome, only one gene cluster, XIS1_460105 to _460116 (present in the center of a single contig) has two AT-domains and six A-domains that correspond to the number of fatty acids and amino acids identified in Xlt [28].

The candidate gene cluster encodes 12 ORFs with predicted NRPS or PKS functions based on BLASTp analysis (Table 7). Eight of these had predicted PKS or PKS-related functions: XIS1_460115 (Type-I PKS), XIS1_460114 (betaketoacyl synthase), XIS1_460113 (PfaD family protein), XIS1_460112 (3-oxoacyl-ACP reductase), XIS1_460111 (thioester reductase), XIS1_460110 (amidohydrolase), XIS1_460107 (Type-I PKS) and XIS1_460105 (acyl-CoA thioesterase) and three had NRPS or NRPS-related

Table 7 Gene location, size and putative function of the candidate $\mathrm{XIt}$ biosynthesis gene cluster from $X$. innexi

\begin{tabular}{|c|c|c|}
\hline Gene location & Size (aa) & Putative function \\
\hline XIS1_460116 & 338 & $\begin{array}{l}\text { Membrane protein of unknown } \\
\text { function }\end{array}$ \\
\hline XIS1_460115 & 1974 & Type-I PKS \\
\hline XIS1_460114 & 1471 & Beta-ketoacyl synthase \\
\hline XIS1_460113 & 948 & $\begin{array}{l}\text { PfaD family proteinglutamate-1-semialdehyde } \\
2,1 \text {-aminomutase }\end{array}$ \\
\hline XIS1_460112 & 255 & 3-oxoacyl-(acyl-carrier-protein) reductase \\
\hline XIS1_460111 & 412 & Thioester reductase/polyketide synthase \\
\hline XIS1_460110 & 258 & $\begin{array}{l}\text { Amidohydrolase/NAD(P)-binding amidase } \\
\text { with nitrilase }\end{array}$ \\
\hline XIS1_460109 & 4437 & NRPS/glutamate racemase \\
\hline XIS1_460108 & 2301 & NRPS \\
\hline XIS1_460107 & 1644 & Type-I PKS/6-deoxyerythronolide-B synthase \\
\hline XIS1_460106 & 539 & Condensation protein/peptide synthase \\
\hline XIS1_460105 & 142 & $\begin{array}{l}\text { Acyl-CoA thioesterase/acyl-CoA thioester } \\
\text { hydrolase }\end{array}$ \\
\hline
\end{tabular}

functions: XIS1_460109 (NRPS), XIS1_460107 (NRPS) and XIS1_460106 (condensation protein).

The arrangement of genes from XIS1_460105 to _460116 is similar to those of the fabclavine synthesis loci found in Xenorhabdus budapestensis DSM 16342 and Xenorhabdus szentirmaii DSM 16338 ( $f c l)$, and prezeamine synthesis loci from Serratia plymuthica AS 9 (zmn) $[73,74]$. We compared the $X$. innexi genes predicted to encode Xlt biosynthesis machinery to $f c l$ and $z m n$ sequences from $X$. szentirmaii and S. plymuthica respectively (the sequences of $X$. budapestensis $f c l$ were not available). BLASTp analysis indicated that the predicted function of each gene in Xlt biosynthesis gene cluster is very similar to both $\mathrm{Fcl}$ and $\mathrm{Zmn}$ coding genes (Table 8). We noted two differences in coding content, both on the flanking edges of the $X$. innexi cluster, relative to $X$. szentirmaii: the first gene in the $X$. szentirmaii locus ( $f c l A$, predicted to encode a NUDIX hydrolase) is absent in the Xlt-encoding cluster (Tables 7 and 8) [74]. Instead, the flanking genes are predicted to encode a TonB homolog and a cardiolipin synthase. Also, $X$. szentirmaii has cluster genes $f c l M$ and $f c l N$, predicted to encode $\mathrm{ABC}$ transporters, immediately downstream of the last condensation domain gene [74]. In contrast, in $X$. innexi the gene following the last condensation domain is predicted to encode an acyl-CoA thioesterase (XIS1_460105). This difference may reflect a distinct release mechanism of the final Xlt product relative to fabclavine and zeamine. Acyl-CoA thioesterases are involved in the release of fatty acids [75] and are most active on myristoyl-CoA but also display high activities on palmoityol-CoA, stearoyl-CoA and arachidoyl-CoA [76-78]. Therefore, it is possible that in $X$. innexi the second PKS module produces 3-oxosaturated fatty acids of the chain length from $\mathrm{C} 14$ to $\mathrm{C} 20$, consistent with the description of preliminary fatty acid structure data for Xlt [28]. The presence of a distinctive acyl-CoA thioesterase encoding gene within the putative Xlt-biosynthetic cluster provides further support that this cluster is involved in the synthesis of Xlt and that Xlt may have unique characteristics relative zeamine/fabclavine.

Various domain analysis programs were used to verify the predicted biosynthetic activities and specificities of the candidate Xlt synthesis gene cluster (see Methods). As expected based on the similarities noted above, the number of A-domains found from XIS1_460105 to _ 460116 was the same as observed for $f c l$ and $z m n$ gene clusters [73, 74]. In fact, the predicted Stachelhause codes from Xlt coding genes were nearly identical to that of $\mathrm{Fcl}$ and $\mathrm{Zmn}$ coding genes (Fig. 7b, Table 2 in [79] and Table 8 in [80]). The peptide moiety incorporated by A-domains in Xlt coding genes closely resembled both $\mathrm{Fcl}$ and $\mathrm{Zmn}$ synthesis genes, and this further suggested that the candidate Xlt biosynthesis gene 
Table 8 Amino acid identities ${ }^{a}$ of predicted proteins encoded by $X$. innexi putative XIt-biosynthetic locus and fabclavine and prezeamine biosynthetic clusters encoded by X. szentirmaii DSM 16338 and Serratia plymuthica AS9 respectively

\begin{tabular}{|c|c|c|c|c|}
\hline \multirow{2}{*}{$\begin{array}{l}\text { Locus tag } \\
\text { XIS1_460116 }\end{array}$} & \multicolumn{2}{|c|}{ Identity (\%) to $X$. szentirmaii $\mathrm{fcl}$ locus } & \multicolumn{2}{|c|}{ Identity (\%) to S. plymuthica zmn locus } \\
\hline & $N / A^{b}$ & - & SerAS9_4283 & $43.03 \%$ \\
\hline XIS1_460115 & $\mathrm{FclC}$ & $69.11 \%$ & SerAS9_4282 & $59.15 \%$ \\
\hline XIS1_460114 & FClD & $74.65 \%$ & SerAS9_4281 & $58.37 \%$ \\
\hline XIS1_460113 & FClE & $79.67 \%$ & SerAS9_4280 & $75.53 \%$ \\
\hline XIS1_460112 & FclF & $81.57 \%$ & SerAS9_4279 & $70.20 \%$ \\
\hline XIS1_460111 & FClG & $76.83 \%$ & SerAS9_4278 & $62.72 \%$ \\
\hline XIS1_460110 & $\mathrm{FclH}$ & $79.46 \%$ & SerAS9_4277 & $65.12 \%$ \\
\hline XIS1_460109 & Fcll & $65.72 \%$ & SerAS9_4276 & $50.79 \%$ \\
\hline XIS1_460108 & FClJ & $70.86 \%$ & SerAS9_4275 & $59.94 \%$ \\
\hline XIS1_460107 & FClK & $67.36 \%$ & SerAS9_4274 & $55.06 \%$ \\
\hline XIS1_460106 & FClL & $65.64 \%$ & SerAS9_4273 & $48.05 \%$ \\
\hline XIS1_460105 & N/A & - & $\mathrm{N} / \mathrm{A}$ & - \\
\hline
\end{tabular}

${ }^{\mathrm{a} B a s e d}$ on the protein blast (BLASTp) analysis

${ }^{\mathrm{b}} \mathrm{N} / \mathrm{A}$ - Not available

cluster is homologous to the $\mathrm{Fcl}$ and Zmn clusters. In $X$. innexi, NRPSpredictor2 predicted $\mathrm{A}_{1}$ through $\mathrm{A}_{6}$ to be $A_{1}$ : serine, $A_{2}$ : phenylalanine, $A_{3}$ : asparagine, $A_{4}$ : asparagine, $\mathrm{A}_{5}$ : threonine, and $\mathrm{A}_{6}$ : valine (Fig. $7 \mathrm{a}$ and $\mathrm{b}$ ). Also, some programs predicted an epimerization domain, which may indicate that the $\mathrm{A}_{3}$-domain incorporates a D-asparagine/aspartic acid. Refinement with Stachelhause codes indicated $90 \%$ probability that $\mathrm{A}_{3}$ and $\mathrm{A}_{4}$ are asparagine and $A_{5}$ is threonine (Fig. 7b). However, consistent with the fact that spectral analysis between 260 and $280 \mathrm{~nm}$ indicates Xlt lacks phenylalanine (J.C. Ensign, unpublished data), the nearest neighbor scores for this amino acid (as well as serine and valine) were low.

in silico analysis of NRPS and PKS modules in the gene cluster from XIS1_460105 to _460116 provided a

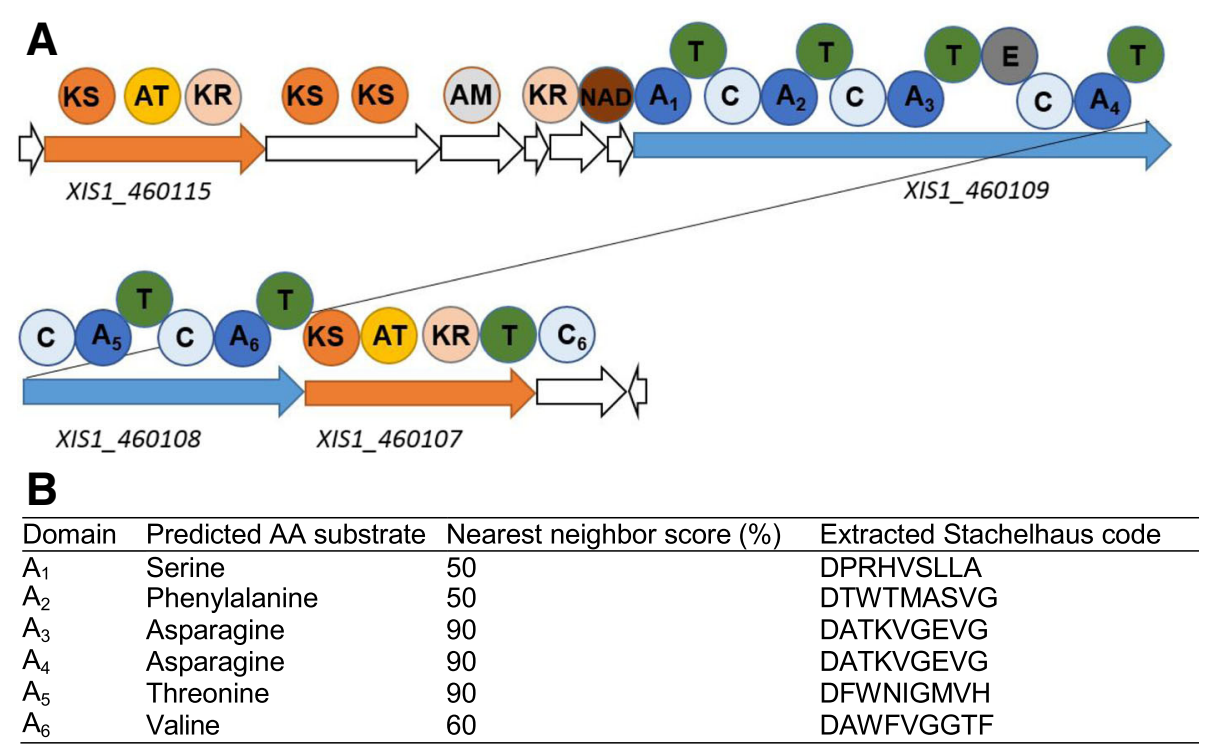

Fig. 7 Predicted NRPS and PKS domains between XIS1_460105 and_460116, and the analysis of adenylation domains. Domains were identified by analyzing translated sequences of each ORF using the Conserved domain search and AntiSMASH. Panel a displays the domain annotation based on the AntiSMASH analysis and Conserved Domain search. Aminotransferase (AT) domain containing ORFs are highlighted in orange and adenylation (A) domain containing ORFs are highlighted in blue. Panel $\mathbf{b}$ represents the predicted amino acid substrate of each adenylation domain from the candidate XIt synthesis NRPS-PKS hybrid cluster from $X$. innexi. The amino acid substrate prediction was made based on the extracted Stachelhause code by NRPSpredictor2 [120]. KS: ketoacyl-synthase, AT: acyl-transferase, KR: ketoreductase, AM: aminotransferase, NAD: NAD(P)-binding amidase, A: adenylation, T: thiolation/peptide carrier protein, E: epimerization 
strong rationale that the selected gene locus is the likely candidate to produce Xlt. This prediction is largely consistent with the preliminary structural analysis of the mosquitocidal toxin, which indicated the presence of serine, asparagine, glycine and at least one oxo-fatty acid of $\mathrm{C}_{8}$ to $\mathrm{C}_{20}$ [28]. The presence of certain amino acid residues of Xlt, including histidine and 2,3-diaminobutyric acid (DAB), could not be explained by the in silico analysis conducted in this study. However, the structural analysis of fabclavine, which is produced by a homologous gene cluster from $X$. szentirmaii and X. budapestensis, showed a replacement of phenylalanine by histidine as well as the presence of 2,3-diaminobutyric acid (DAB) in its peptide moiety. The structure of fabclavines, which corresponds to the preliminary structural data of Xlt, provided further support that the selected gene cluster should produce Xlt. Based on our prediction, we next tested if mutation of the gene cluster from XIS1_460105 to _460116 would disrupt mosquitocidal toxin activity in $X$. innexi.

\section{Site-directed mutagenesis at XIS1_460115 or XIS1_460109 resulted in phenotypic changes}

To further explore the possibility that the candidate gene cluster is involved in Xlt mosquitocidal toxin biosynthesis, we used site-directed mutagenesis to mutate two independent genes within the locus: XIS1_460115 and XIS1_460109. Each was individually replaced with a kanamycin cassette (see Methods) and supernatants from the resulting XIS1_460115::kan (DXIS1_460115) and XIS1_460109::kan (DXIS1_460109) mutants were analyzed with MALDI-TOF MS. Consistent with previous preliminary data, which indicated that Xlt has a molecular weight range between 1182 and $1431 \mathrm{Da}$, with the difference in molecular weights ascribed to varying lengths of fatty acids [28], our MALDI-TOF MS analysis of wild type $X$. innexi (HGB1681) supernatant revealed major peaks between 1348 and $1402 \mathrm{Da}$ (Additional file 9). In contrast the supernatants of $\triangle X I S 1 \_460115$ and $\triangle X I S 1$ 460109 did not have peaks in this region and rather showed either one major peak at $751 \mathrm{Da}$ or three major peaks between 1182 and $1210 \mathrm{Da}$, respectively (Additional file 9).

Bioassays were conducted to examine if the mutation of XIS1_460115 or XIS1_460109 resulted in reduction or loss of the mosquito larvicidal activities, as predicted if the candidate gene cluster locus is necessary for Xlt biosynthesis. Of the mosquito larvae exposed to wild type $X$. innexi supernatant, $100 \%$ mortality was observed, up to $25 \%$ dilution of the supernatant (Fig. 8). Exposure to dilutions of $12.5 \%$ and $6.25 \%$ of supernatant resulted over $70 \%$ of mortality in $48 \mathrm{~h}$ (Fig. 8). However, both $\triangle X I S 1 \_460115$ and $\triangle X I S 1 \_460109$ culture supernatants were inactive at dilutions of $25 \%$ or lower (Fig. 8), and

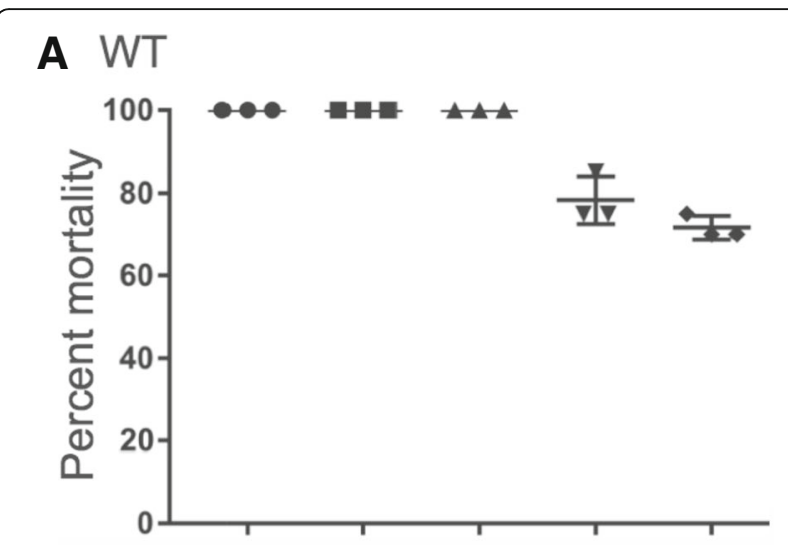

B $\Delta X I S 1 \_460115$

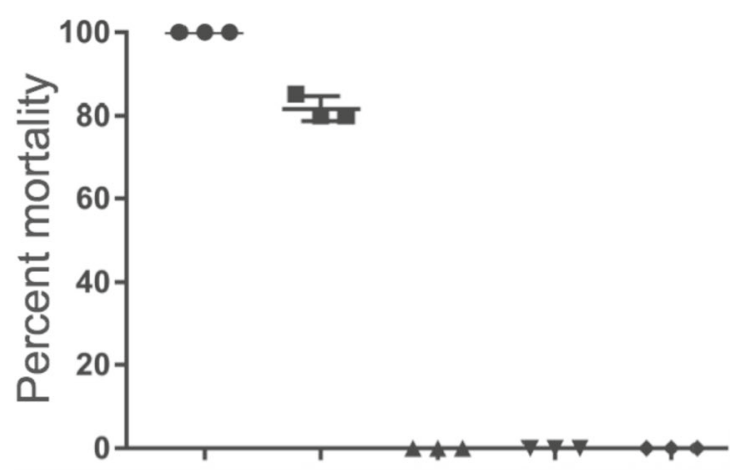

C $\Delta X I S 1 \_460109$

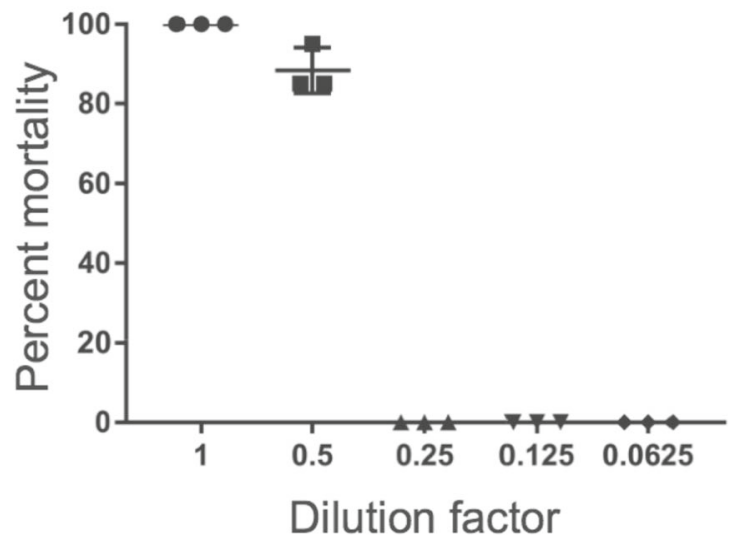

Fig. 8 Percent mortality of late 3rd instar Ae. aegypti larvae after treatment with dilutions of culture supernatants of WT $X$. innexi, $\triangle X I S 1$ 460109 and AXIS1_460115. Half-fold serial dilutions of cellfree supernatants from cultures of (a) wild type $X$. innexi, $\mathbf{b}$ the XIS1_460115::kan mutant (AXIS1_460115), or (c) the XIS1_460109:: kan mutant (AXIS1_460109) were bioassayed with 20 larvae per concentration. Mortality was recorded at 48 h. Each data point indicates a single experiment ( $n=3$ experiments). No mortality was observed after larvae incubation in 0.25 dilution or lower of AXIS1_460109 and AXIS1_460115 supernatants but over 70\% mortality was observed in the lowest test concentration of WT $X$. innexi supernatants 
only the undiluted supernatants from these mutants resulted in $100 \%$ mortality (Fig. 8 ).

\section{Discussion}

Xenorhabdus bacteria, symbionts of Steinernema nematodes, are increasingly exploited for novel products that may be useful in pharmaceutical, agricultural, and industrial settings [81]. Further, exploration of the biology of Xenorhabdus-Steinernema associations is yielding new insights into molecular and cellular biology and evolutionary and ecological principles underlying parasitism (e.g. $[1,82,83])$. In this study, we used $X$. innexi and its nematode host $S$. scapterisci, which specializes in parasitism of crickets, to expand our knowledge of potential virulence determinants produced by Xenorhabdus bacteria and to discern how $X$. innexi may be impacted by specialization. Our findings that $X$. innexi is an ineffective pathogen of several insects tested, that it does not secrete immunosuppressive factors, and that the $X$. innexi genome lacks many of the canonical virulence determinants encoded by its sister species may indicate that specialization in crickets has led to an erosion of virulence coding potential. However, the specificity of $S$. scapterisci for colonization by $X$. innexi, and our identification of several loci predicted (e.g. T6SS/Rhs) or confirmed (e.g. $x l t$ ) to be necessary for production of secreted factors indicate that $X$. innexi remains an actively transmitted and biologically active symbiont.

Relative to the well-characterized entomopathogenic nematode symbiont $X$. nematophila, $X$. innexi is attenuated for virulence and reproduction in the lepidopteran hosts G. mellonella and M. sexta, as well as the dipteran $D$. melanogaster. Unpublished data suggests $X$. innexi is also avirulent towards honeybees (Apis mellifera) and Colorado potato beetles (Leptinotarsa decemlineata) [29]. This suggests that the toxicity of the S. scapterisci$X$. innexi pair either relies on the nematode or on an emergent synergism that we did not detect when using the bacteria alone [11].

\section{Common genomic features of Xenorhabdus species with attenuated virulence phenotypes}

$X$. innexi joins a growing list of Xenorhabdus species that displays attenuated virulence relative to other members of the genus. Other examples include $X$. poinarii G6, which is attenuated for virulence when injected into Spodoptera littoralis and G. mellonella insects. Its genome is smaller (3.66 Mbp) than that of either X. nematophila (ATCC19061) or X. bovienii (SS-2004) and lacks hemolysins, T5SS, Mcf, NRPS, and TA systems [7], suggesting a streamlining of the genome. In contrast, we report here that the genome of $X$. innexi is of similar size (slightly larger) as those of $X$. nematophila and $X$. bovienii, and while it lacks Tc toxins, Mcf, and other canonical Xenorhabdus virulence determinants, it does contain genes predicted to encode hemolysins and other T5SS genes and non-ribosomal small molecule biosynthetic machinery, including a locus necessary for production of an extracellular mosquitocidal small molecule. Although caution is necessary when interpreting data based on a draft genome, we propose that in contrast to $X$. poinarii, the $X$. innexi attenuated virulence is due not to genome reduction, but rather to the presence of a distinct repertoire of genes.

In this sense, the $X$. innexi genome may be more similar to $X$. bovienii CS03, the symbiont of $S$. weiseri, another attenuated virulent Xenorhabdus bacterium [4]. In this case, rather than genome reduction (as in X. poinarii) the attenuated virulence appears to be associated with a genome shift away from virulence determinants and towards inter-bacterial competition. Both $X$. bovienii and $X$. innexi have genomes that are larger than those of $X$. nematophila and X. bovienii (SS-2004). Bisch et al. [4] proposed that the $X$. bovienii (CS03) genome had been shaped by the selection for factors mediating intermicrobial competition. A similar phenomenon may be occurring in $X$. innexi, an idea supported by the presence of T6SS and Rhs homologs, which in other systems mediate inter-bacterial competition, concomitant with an absence of canonical insect virulence determinants.

Curiously, X. poinarii, X. bovienii CS03, and X. innexi all lack, or have degraded genes encoding Tc toxins [4, 7]. It should be noted that the production of Tc toxins is not a requirement for virulence, since the Clade $C_{I}$ bacterium, $X$. doucetiae is virulent in both $S$. littoralis and G. mellonella, even though it does not produce Tc toxins [7]. Ogier et al. [7] suggested that the absence of Tc toxins encoded in genomes of members of this clade $\left(C_{\mathrm{I}}\right)$ [84] is due to loss of an ancestral component [7]. In the $X$. innexi genome we did not find evidence of fragments or pseudogenized copies of Tc-encoding genes, as are present in the X. bovienii CS03 genome [4]. As such, we propose that the apparent lack of these genes in the genome of $X$. innexi, a member of clade $\mathrm{C}_{\mathrm{IV}}$ indicates a loss event, separate from that proposed to have occurred in clade $\mathrm{C}_{\mathrm{I}}$. Interestingly, in the draft genome of another strain of the $C_{\mathrm{IV}}$ clade ( $X$. cabanillasii, accession number: GCA_000531755), Tc loci are incomplete, which supports the idea that recent deletions for Tc-encoding genes have occurred in this clade (unpublished data, S. Gaudriault). Regardless, our data combined with those of Ogier et al. [7] and Bisch et al. [4] indicate that the presence of Tc-encoding genes is not a uniformly present trait among Xenorhabdus species. It may be that Tc toxins are generalized insecticidal factors that are not of adaptive benefit to Xenorhabdus with narrow host ranges. Although not investigated for $S$. weiseri- X. bovienii CSO3 pair, both $S$. scapterisci-X. innexi and $S$. 
glaseri-X. poinarii symbiont pairs appear to have a restricted host range relative to other SteinernemaXenorhabdus pairs [7, 19, 85-87].

\section{A hybrid NRPS/PKS locus is necessary for X. Innexi mosquitocidal toxicity}

Despite the ineffectiveness of $X$. innexi as a pathogen when injected into members of various orders of insects, cell-free supernatants from $X$. innexi do exhibit toxicity specifically towards larvae of Aedes, Anopheles and Culex mosquitoes [28]. Our bioinformatic analysis of the $X$. innexi genome revealed a candidate hybrid NRPS/ PKS for the biosynthesis of a secreted mosquitocidal toxin. This prediction is supported by our experimental data showing reduction of Xlt lipopeptide synthesis in and mosquitocidal toxicity of the XIS1_460115 or XIS1_460109 supernatants. Entomopathogenic bacteria, including $X$. innexi, produce a diversity of secondary metabolites including antibiotics, antifungal and other virulence factors [88] and it is possible that the loss of mosquitocidal toxicity in the XIS1_460115 and XIS1_460109 mutants is due to disruption an indirect impact on these other pathways. However, the combined bioinformatic and genetic evidence more strongly support a direct role for the Xlt biosynthetic machinery in the production of the mosquitocidal lipopeptide.

The Xlt biosynthesis gene cluster we have identified is homologous to $f c l$ and $\mathrm{zmn}$ clusters in the genomes of $X$. szentirmaii and S. plymuthica that encode machinery for the synthesis of a class of lipopeptides known as fabclavines and zeamines. Xlt biosynthesis gene cluster also differed from $f c l$ and $z m n$ cluster by the presence of acyl-CoA thioesterase at the end of the cluster as well as the lack of NUDIX hydrolase gene in the N-terminus and $\mathrm{ABC}$ transporter genes in the $\mathrm{C}$-terminus. This genetic similarity and difference, combined with the similar mass to charge ratios of Xlt and fabclavines $(\sim 1347)$ supports the idea that Xlt is a derivative within the fabclavine family. $X$. budapestensis and $X$. szentirmaii produce multiple forms of fabclavine, some of which are distinguished by the presence of either a histidine or phenylalanine moiety at the 2 position. Since Xlt does not absorb at $280 \mathrm{~nm}$ (J. Ensign, unpublished data) it is unlikely to contain phenylalanine and thus Xlt is a derivative of a fabclavine Ib [74].

Fabclavines, and the related zeamine have a broad spectrum of bioactivity against bacteria, fungi, nematodes, oomycetes, apicomplexans, and protozoa [79, 80, 89-92]. Similarly, Xlt demonstrated antimicrobial activities towards a broad spectrum of bacteria including Pseudomonas aeruginosa, Salmonella spp., Escherichia coli, Listeria monocytogenes, and Bacillus cereus [28].

The results presented here expand the list of fabclavine targets to include mosquito larvae. The literature includes multiple reports of Steinernema-Xenorhabdus activities against mosquitoes, which our data suggest could be mediated by bacterially-produced fabclavine and fabclavine derivatives. For instance, $S$. carpocapsae (the nematode host of $X$. nematophila) triggers an immune response in and can kill the larvae of Aedes aegypti, a vector of many diseases of humans [73, 93]. Although the mechanism underlying this observation was not investigated, the authors of these studies suggested it could involve a secreted toxin. In support of this concept, recent studies demonstrated toxicity toward Ae. aegypti larvae of cell-free supernatants from $X$. nematophila, the symbiont of $S$. carpocapsae [74]. Mosquitoes are unlikely to be natural hosts of SteinernemaXenorhabdus species complexes in nature, raising the question of what the biological function of Xlt may be in the $X$. innexi life history. One possibility may be that it acts in inter-microbial competition, since as a lipopeptide Xlt may be able to disrupt bacterial cell membranes through detergent-like action [94, 95]. Certain bacterial lipopeptides such as surfactins and cyclic lipopeptides (CLPs) from Bacillus subtilis have both insecticidal and antimicrobial activity [96-99], although their mode of action against insects is not well understood.

It should be noted that while fabclavines as a class clearly have a broad target spectrum, moiety substitutions within individual fabclavine derivatives could result in varying and specialized activities. In turn, if Xlt and other Xenorhabdus-produced fabclavines have nondiscriminant broad-spectrum bioactivities, it will be of interest to determine how Steinernema nematode hosts associated with the fabclavine-producing Xenorhabdus symbionts survive exposure to this generally toxic compound.

\section{Conclusions}

As a basis for continued exploration of $X$. innexi in biological studies and biotechnological applications we examined some of its characteristics. We found that unlike other reported EPN/bacterial symbioses, S. scapterisci is colonized at very low levels and that $X$. innexi has attenuated virulence compared to other species of Xenorhabdus. We have sequenced a draft version of the $X$. innexi genome and reported detailed analyses of several families of known virulence factors. We found no evidence for several key Xenorhabdus spp. toxicity genes, including Tc toxins and "makes caterpillars floppy" (Mcf) toxins. However, we also found that the $X$. innexi genome contains two-partner secretion (TPS) system genes from all three TPS clusters, including CdiA exoproteins, active hemolysins, and TpsA proteins. Consistent with other Xenorhabdus spp. genomes, we found numerous loci predicted to encode non-ribosomal peptide synthetases, which we explored and identified a 
locus that putatively encodes a fabclavine derivative with mosquitocidal activity. The $X$ innexi genome will be a valuable resource in identifying loci encoding new metabolites of interest, but also in future comparative studies of nematode-bacterial symbiosis and niche partitioning among bacterial pathogens.

\section{Methods}

\section{Bacterial strains and growth conditions}

Strains and plasmids used in this study are listed in Table 1. Two $X$. innexi strains were tested. One, HGB1681 (a.k.a. PTA-6826), is a lab stock strain acquired by Prof. Jerry Ensign (UW-Madison) from Prof. Grover Smart (University of Florida), the other was isolated from $S$. scapterisci nematodes provided by BD Scientific. In both cases the primary form was isolated as blue colonies on NBTA plates [100]. Xenorhabdus strains were incubated at $30{ }^{\circ} \mathrm{C}$ in media not exposed to light, or supplemented with $0.1 \%$ pyruvate [101]. Permanent stocks of the cultures were stored in broth supplemented with $20 \%$ glycerol at $-80{ }^{\circ} \mathrm{C}$. Luria Bertani (LB) was used for standard growth, and lipid agar (LA) was used for nematode-bacterium co-culture [102]. When noted, media were supplemented with ampicillin (150 $\mu \mathrm{g} / \mathrm{ml})$, kanamycin $(50 \mu \mathrm{g} / \mathrm{ml})$, streptomycin $(150 \mu \mathrm{g} / \mathrm{ml})$, or diaminopimelic acid (DAP) $(80 \mu \mathrm{g} / \mathrm{ml})$.

To determine the in vitro growth rate of $X$. innexi, we subcultured overnight cultures to an OD600 of 0.1 in LB with limited light exposure and grew them in a 96 well plate (Sarstedt 82.1581 .001 ), $200 \mu \mathrm{l}$ /well with liquid only (no cultures) in the outermost wells. The plate was incubated in a BioTech plate reader at $30{ }^{\circ} \mathrm{C}$ for $17 \mathrm{~h}$ constantly shaking in a double orbital pattern, measuring $\mathrm{OD}_{600}$ every hour. $X$. nematophila and $X$. bovienii were included for comparison. For each species, three biological replicates were measured, each with three technical replicates within the 96-well plate. The technical replicates were averaged for each biological replicate, and then the biological replicates were plotted with the standard error of the mean. The in vivo growth rates of $X$. nematophila and $X$. innexi in D. melanogaster were calculated using the number of CFU (N1) at time 0 (t1) and the number of CFU (N2) recovered at $6 \mathrm{HPI}(\mathrm{t} 2)$, using the following formula $\ln (\mathrm{N} 2 / \mathrm{N} 1)=\mathrm{k}(\mathrm{t} 2-\mathrm{t} 1)$.

\section{Animal sources and husbandry}

After purchase from a local vendor (Reptile Rapture, Madison, WI or PetSmart, Knoxville, TN) A. domesticus were stored in a large bucket and provided with apple slices and fresh spinach. S. scapterisci nematodes were obtained from Becker Underwood Inc. and BD Scientific and established in the laboratory through infection of Acheta domesticus house crickets. Typically, 20 crickets were used for infection with $S$. scapterisci nematodes, while 5 were left uninfected as controls. Crickets were infected within 1-2 days of purchase. Nematodes were propagated every 8 weeks. For infections a $100 \mathrm{~mm}$ diameter filter paper was placed in the top of an inverted $100 \mathrm{~mm}$ petri dish in which holes had been burned to allow airflow. The filter paper was soaked with $1 \mathrm{ml}$ of $S$. scapterisci IJ stock from the previous infection round, stored in $\mathrm{H}_{2} \mathrm{O}$. In each dish, 3-4 live crickets were placed and provided fresh spinach or apple slices. Infection with $\sim 100 S$. scapterisci IJs per individual A. domesticus cricket yielded $90 \pm 0 \%$ mortality $(n=4 ; 10-20$ insects per trial) within 2-3 d of exposure, and some within $1 \mathrm{~d}$. This rapid host killing is a hallmark characteristic of EPNs [103] and reflects efficient release of the bacterial symbiont and/or the release of toxic factors by the nematodes themselves. Once crickets died, the cadavers were placed onto $60 \mathrm{~mm}$ filter paper in a $60 \mathrm{~mm}$ petri dish, which was then set in a water-filled $100 \mathrm{~mm}$ petri dish. After 2-3 days IJs were visible on cadavers and after an additional 4 days IJs emerged from the host and thousands of progeny migrated into the water trap. The nematodes were stored in $\mathrm{H}_{2} \mathrm{O}$ for up to 16 weeks. A Stereo Star dissection microscope was used to visually monitor $A$. domesticus infection and collect photos shown in Additional file 8.

Inbred laboratory Aedes aegypti (Rockefeller strain) larvae were reared at $26{ }^{\circ} \mathrm{C}$ under a $14 \mathrm{~L}: 10 \mathrm{D}$ photoperiod and provided with pellets of fish food [104]. Late 3rd instars were used to bioassay for the presence of mosquito larvicidal lipopeptide, Xlt.

Drosophila melanogaster Oregon- $\mathrm{R}$ strain used for infection experiments were kept in standard fly bottles containing dextrose medium (129.4 g dextrose, $7.4 \mathrm{~g}$ agar, $61.2 \mathrm{~g}$ corn meal, $32.4 \mathrm{~g}$ yeast, and $2.7 \mathrm{~g}$ tegosept per liter; polypropylene round bottom $8 \mathrm{oz}$. bottles plugged with bonded dense weave cellulose acetate plugs, Genesee Scientific Cat \#49-100) and were housed at $25{ }^{\circ} \mathrm{C}$ with $60 \%$ relative humidity and a $12 \mathrm{~h}$ light and $12 \mathrm{~h}$ dark cycle, as previously described [105].

Galleria mellonella waxworms used for infection experiments were purchased from CritterGrub (http://www.crittergrub.com/). Once received, any dead waxworms were discarded and the healthy individuals were kept at $15{ }^{\circ} \mathrm{C}$ in the dark until used for experiments. All waxworms were used for experimentation within 14 days.

Tobacco hornworm Manduca sexta larvae were raised from eggs (obtained from Carolina Biological Supply Company) on artificial diet (Gypsy moth wheat germ diet, MP Biomedicals, Aurora, $\mathrm{OH}$ ) with a photoperiod of $16 \mathrm{~h}$.

\section{In vitro colonization assays}

After overnight incubation, lawns of $X$. innexi were inoculated with $1 \mathrm{ml}$ of $S$. scapterisci stock and incubated at 
room temperature for $72 \mathrm{~h}$ or until a large number of adult nematodes were visible. Axenic eggs were isolated from these nematodes as previously described [30] and resuspended in $5 \mathrm{ml}$ LB supplemented with ampicillin. The eggs were used immediately or allowed to hatch into J1 juveniles and stored at room temperature for up to 3 days. The absence of contamination was visually confirmed before use. Approximately 500-1000 axenic eggs and/or J1 nematodes were placed onto lipid agar plates with bacterial lawns and allowed to incubate at room temperature for 3-5 days before placement into White traps to capture emerging IJs [106]. To assess bacterial colonization of IJs, 1000 IJs were prepared by surface sterilizing in $1.7 \%$ sodium hypochlorite solution (5 ml KOH, $32 \mathrm{ml} \mathrm{5.25 \%} \mathrm{sodium} \mathrm{hypochlorite} \mathrm{[Clorox}$ bleach], and $63 \mathrm{ml} \mathrm{ddH20)} \mathrm{for} 2 \mathrm{~min}$ followed by rinsing 6 times in $\mathrm{ddH}_{2} \mathrm{O}$. Approximately 200 surface sterilized IJs (in $200 \mu \mathrm{l}$ ) were homogenized for $2 \mathrm{~min}$ with a handheld motor driven grinder and sterile polypropylene pestle (Kontes). The homogenate was dilution plated to observe and quantify CFU.

\section{Construction of $X$. innexi strains expressing the green fluorescent protein (GFP)}

To visualize $X$. innexi within nematodes, we engineered it to express the green-fluorescent protein. pBSL118, a mini Tn5-GFP donor plasmid was used in combination with S17-1 גpir from pUX-BF13, a Tn5 helper strain, to perform GFP conjugations [30, 107, 108]. Briefly, donor, recipient, \& helper strain were streaked for single colonies on $\mathrm{LB}+$ pyruvate agar plates and grown for 24$48 \mathrm{~h}$ at $30{ }^{\circ} \mathrm{C}$ without exposure to light. Single colonies were picked grown overnight at $30{ }^{\circ} \mathrm{C}$ in liquid $\mathrm{LB}$, with supplementation with $300 \mu \mathrm{M}$ diaminopimelic acid for the helper and donor strain. Cells were subcultured into fresh medium and grown for an additional $4 \mathrm{~h}$ after which $900 \mu$ lof $X$. innexi (HGB1681 or HGB1997) and $300 \mu \mathrm{l}$ each of the helper and donors strains were pelleted separately, washed and re-suspended at their original volumes. The three strains were then mixed together, and plated as a single spot onto a permissive LB pyruvate + DAP plate. After $24 \mathrm{~h}$ incubation an inoculation loop was dragged through the spot and the collected cells were re-suspended in LB and plated onto a selective LB pyruvate with ampicillin and kanamycin. After $24-48 \mathrm{~h}$ incubation at $30{ }^{\circ} \mathrm{C}$ the resulting colonies were analyzed for the expression of GFP with a Nikon Eclipse TE300 inverted fluorescent microscope.

\section{Bacterial infection of insects}

Injections into $D$. melanogaster adults were performed as previously described [105]. Briefly, different colony forming unit (CFU) doses were injected into $\mathrm{CO}_{2}$ anesthetized adult male flies aged 5-7 days old with control flies being injected with PBS. Each fly received a total volume of $50 \mathrm{nl}$ injections in the anterior abdomen. Injections were performed using a MINJ-FLY high-speed pneumatic injector (Tritech Research, CA) and a pulled glass needle. After each injection all flies were maintained at $25{ }^{\circ} \mathrm{C}$ and $60 \%$ humidity. The bacteria were grown to log phase and then diluted to obtain the desired CFU count in a $50 \mathrm{nl}$ volume. To determine CFUs in infected flies, individual flies were homogenized in $200 \mu \mathrm{l}$ of PBS, diluted serially, and spotted $50 \mu \mathrm{l}$ onto LB plates supplemented with $0.1 \%$ sodium pyruvate. Plates were kept overnight at $28{ }^{\circ} \mathrm{C}$ and total CFUs were then determined. For each virulence experiment we injected $\geq 60$ flies, per dose of bacteria. Each experiment was repeated three times. For each in vivo growth assay, we injected and homogenized $\geq 10$ flies, per dose at each time point. These experiments were repeated in triplicate.

Injections into G. mellonella larvae were performed as previously described [33]. Briefly, different colony forming unit (CFU) doses were injected into $\mathrm{CO}_{2}$ anesthetized 6th instar larvae. The larvae weighed between 0.19 and $0.30 \mathrm{~g}$. We injected $10 \mu \mathrm{l}$ in to the hindmost left proleg using a 27-gauge needle. After injections, all insects were kept in $60 \mathrm{~mm}$ petri dishes in the dark at $25{ }^{\circ} \mathrm{C}$. Mortality was checked every $12 \mathrm{~h}$. To determine CFUs in infected waxworms, we extracted approximately $10 \mu \mathrm{l}$ of hemolymph from individual larvae and diluted this with $190 \mu \mathrm{l}$ of PBS. The diluted hemolymph was then diluted serially, and $50 \mu \mathrm{l}$ was spotted onto LB plates supplemented with $0.1 \%$ sodium pyruvate. Plates were kept overnight at $28{ }^{\circ} \mathrm{C}$ and total CFUs were then determined. For each virulence experiment we injected $\geq 10$ larvae, per dose of bacteria. These experiments were repeated experiments in triplicate. For each growth assay, we injected and bled $\geq 10$ larvae, per dose. These experiments were repeated in triplicate.

For injections into $M$. sexta, fifth-instar insect larvae were incubated on ice for approximately $10 \mathrm{~min}$ prior to injection. Ten microliters of the diluted culture were injected behind the first set of prolegs of each of 10 insect larvae per treatment using a 30-gauge syringe (Hamilton, Reno, NV). Dilution plating of the inoculum confirmed that for each treatment, an individual insect received $10^{4} \mathrm{CFU}$.

\section{Activation of the proPO system in insect plasma}

Supernatants of $X$. innexi and $X$. nematophila strains were used to test their proPO inhibitory activity. Bacterial cultures were grown in LB broth for $\sim 18 \mathrm{~h}$ at $30{ }^{\circ} \mathrm{C}$ and bacterial supernatant was isolated by spinning cells for $5 \mathrm{~min}$ at $8000 \mathrm{x} \mathrm{g}$ and filtering through a $0.2 \mu \mathrm{m}$ syringe filter. Filtered supernatants were heat-treated for $10 \mathrm{~min}$ at $95{ }^{\circ} \mathrm{C}$ to inactivate heat-labile factors in the supernatant. 
Hemolymph (plasma) from wounded fifth instar $M$. sexta larvae was harvested as described previously [109]. In vitro activation of the proPO system was assessed by combining the following in wells of a 96-well plate: $150 \mu \mathrm{l}$ PBS (phosphate-buffered saline; $137 \mathrm{mM} \mathrm{NaCl}$, $2.7 \mathrm{mM} \mathrm{KCL}, 10 \mathrm{mM} \mathrm{Na} \mathrm{HPO}_{4}, 1.8 \mathrm{mM} \mathrm{KH} \mathrm{PO}_{4}$, $\mathrm{pH}$ 7.4), $10 \mu \mathrm{l}$ plasma, and $20 \mu \mathrm{l}$ of bacterial supernatant (filtered through a $0.20 \mu \mathrm{m}$ syringe filter). Fresh LB was used as a negative control. This reaction was incubated at room temperature with constant shaking for $30 \mathrm{~min}$ to allow time for inhibition of proPO activation. Immediately following incubation, $20 \mu \mathrm{l}$ of L-dihydroxyphenylalanine (L-DOPA) ( $4 \mathrm{mg} / \mathrm{ml} \mathrm{PBS}$ ) were added to the reaction. A microplate reader was used to monitor absorbance at $490 \mathrm{~nm}$ every min for $1 \mathrm{~h}$. proPO activation was measured by calculating the rate of synthesis of dopachrome (a melanin intermediate) from L-DOPA. Data are presented as the percentage of each treatment against a negative control for proPO inhibition.

\section{DNA extraction, genome sequencing and annotation}

The $X$. innexi genomic DNA was isolated using a standard protocol [110] and submitted for Roche (454) pyrosequencing and assembly at the University of Wisconsin Biotechnology Center. The assembled genome sequence was annotated using the Magnifying Genomes server (MaGe) from MicroScope Microbial Genome Annotation and Analysis Platform. Sequences are available through accession numbers: FTLG01000001-FTLG01000246.

\section{Identification of putative toxin genes in X. nematophila and $X$. innexi}

The X. nematophila ATCC19061 genome was used as a reference to identify the various toxin gene families that we evaluated [104]. We determined the presence or absence of genes encoding putative toxins in $X$. innexi in three ways: using $X$. nematophila sequences as BLAST queries $(\mathrm{E} \leq 0.00005)$ [111], performing Pfam analyses to identify the presence of Pfam domains associated with the various toxin proteins, and using the MicroScope Gene Phyloprofile tool [42] to identify sets of genes specifically absent in $X$. innexi genome. For BLAST analyses, we used the following $X$. nematophila genes as queries: MARTX (XNC1_1376, 1377, 1378, 1380, 1381); Mcf (XNC1_2265); Pir toxins (XNC1_1142, and XNC1 _1143); PrtA (XNC1_4025); Tc toxins A (XNC1_2333+ 2334, XNC1_2560+2561, XNC1_2566, XNC1_2569, X $\mathrm{NC1} 13020+3021+3022+3023+3024$, and XNC1_2187 ); B (XNC1_2186, XNC1_2335, XNC1_2568); and C (X NC1_2188, XNC1_2336, XNC1_2567); chitinases (XNC 1_2562 and XNC1_2569); Txp40 (XNC1_1129); ХaxAB (XNC1_ 3766 and XNC1_3767); Xenocin (XNC1_12211223). For Pfam searches we used hmmscan from the latest version of HMMER (3.0) software package, which implements probabilistic profile hidden Markov models. We set our threshold $E$-value criterion at $10^{-6}$, to reduce the probability of false-positive matches. For MaGe analyses we used loci present in the completely sequenced genome of the virulent strain $X$. nematophila (ATCC 19061) and identified those with homologs in the genomes of the virulent strains $X$. bovienii SS-2004 and $X$. doucetiae FRM16 $[6,7]$, but without homologs in the $X$. innexi HGB1681 genome. The following homology constraints were used: bidirectional best hit, minimal alignment coverage of 0.8 , and amino acid sequence identity of $30 \%$.

\section{Identification and analysis of Tps genes in $X$. innexi}

TpsA proteins sequences were aligned using the CLUSTAL W program implemented in SEAVIEW [112], and alignments were cleaned using Gblocks [113]. The phylogenetic trees were built by the maximum likelihood (ML) method using the LG substitution model, and branch support values, estimated by the aLRT (SH-like) method, are indicated at the nodes.

Search for type III secretion system homologs in $X$. innexi The Type III Secretion (T3S) genes (Additional file 4) of Salmonella enterica (NCBI Reference Sequence NC_003197.2) were used to search for homologs in $X$. innexi. The nucleotide sequence of the genes in Additional file 4 were used as query sequences in a nucleotide BLAST performed with the Magnifying Genomes server (MaGe) from MicroScope Microbial Genome Annotation and Analysis Platform. Consistent with other examined species of Xenorhabdus, X. innexi did not contain homologs for any T3S genes.

\section{NRPS-PKS hybrid cluster domain analysis and identification of a candidate XIt biosynthetic gene cluster in $X$. innexi}

$X$. innexi genome was screened to locate NRPS, PKS and NRPS-PKS hybrid gene clusters. The initial screening was conducted by analyzing protein sequences of each coding DNA sequence (CDS) through a conserved domains search in National Center for Biotechnology Information (NCBI). If a conserved domain search recognized the candidate gene sequence as NRPS, PKS or NRPS-PKS hybrid, the number of A- or AT- domains were examined. NRPS, PKS and NRPS-PKS hybrid genes identified were further analyzed by submitting the corresponding protein sequences into the antibiotic and secondary metabolite analysis shell (AntiSMASH) to identify NRPS and PKS domains [114]. The data file generated by AntiSMASH analyses of the candidate gene cluster is available in Additional file 10.

One candidate gene cluster predicted to encode the Xlt biosynthetic machinery was identified based on 
Table 9 Primers used in this study

\begin{tabular}{|c|c|c|}
\hline Primers & $5^{\prime}$ to $3^{\prime}$ sequence ${ }^{a}$ & Use \\
\hline XIS1_460109ApaUpF & NNNNNNGGGCCCCAGGATATGCCATTCAGC & Mutant construction \\
\hline XIS1_460109BamUpR & NNNNNNGGATCCCAATGACATCAGGCACAC & Mutant construction \\
\hline XIS1_460109BamDnF & NNNNNNGGATCCGAACCATCGCAGATTGAG & Mutant construction \\
\hline XIS1_460109XbaDnR & NNNNNNTCTAGAGCCCAATCGCTTCATATC & Mutant construction \\
\hline XIS1_460115ApaUpF & NNNNNNGGGCCCGAATCGCCCTGGATTATG & Mutant construction \\
\hline XIS1_460115BamUpR & NNNNNNGGATCCCCCTCTGGCTGATAATAG & Mutant construction \\
\hline XIS1_460115BamDnF & NNNNNNGGATCCCTCAGGCTCGATTATTGG & Mutant construction \\
\hline XIS1_460115XbaDnR & NNNNNNTCTAGACTGAATGTACTCCTGCTG & Mutant construction \\
\hline NilBF & NNNCATATGAGGAAAACGCCACATTCCGG & Confirmation PCR \\
\hline NilBR & NNNGGGCCCTTGCATGGTTTGGTTG & Confirmation PCR \\
\hline M13F $(-20)$ & GTAAAACGACGGCCAG & Sequencing PCR \\
\hline M13R & CAGGAAACAGCTATGAC & Sequencing PCR \\
\hline
\end{tabular}

${ }^{a} \mathrm{~N}$ represents $\mathrm{A}, \mathrm{T}, \mathrm{G}$ or $\mathrm{C}$. Engineered restriction enzyme sites are underlined

preliminary chemical data on Xlt structure and composition. Additional in silico analyses were conducted to further test this prediction. Protein sequences of each ORF in the cluster were examined through protein BLAST to predict the putative function, and then analyzed through the conserved domain search to identify PKS, NRPS and non-PKS/NRPS domains. Protein sequences of A-domains in NRPS modules were analyzed through NRPSpredictor2 [115] and AT- domains identified in PKS modules were analyzed using I-TASSER server [116].

\section{Construction of XIS1_460115 and XIS1_460109 mutants}

To provide a functional test of the role of the candidate $x l t$ gene cluster in Xlt biosynthesis, we used allelic exchange site-directed mutagenesis to replace the PKS (XIS1_460115) or NRPS (XIS1_460109) genes with a kanamycin cassette [117] and tested relevant phenotypes of the resulting mutants. Briefly, upstream and downstream regions of XIS1_460115 or XIS1_460109 were amplified using restriction-site-containing primers (Table 9). Amplified fragments were cloned individually into pBluescript SK (-) plasmids; the kanamycin resistant cassette from pKanWor plasmid was cloned into the BamHI site of pBlueXIS1_460109UpDn or pBlueXIS1_460115UpDn (Table 1). The pBlueXIS1_460109UpDn or pBlueXIS1_460115UpDn construct was cloned into a pKR100 suicide vector; the resulting pKRXIS1_460115 and pKRXIS1_460109 constructs (Table 1) were separately conjugated into the WT $X$. innexi using $E$. coli S-17 $\lambda$ pir donor strain. The resulting mutants were first verified by PCR amplification of nilB, which is a Xenorhabdus-specific gene [118]. The position of mutation was also confirmed by PCR amplification of the flanking regions of the inserted kanamycin cassette.

\section{Mosquito larvicidal bioassays}

Mosquito larval bioassays were conducted to determine if mutation at XIS1_460115 or XIS1_460109 resulted in the loss of mosquito larvicidal activity. WT $X$. innexi, $\triangle X I S 1 \_460115$ and $\Delta X I S 1 \_460109$ were grown in liquid LB media overnight at $30{ }^{\circ} \mathrm{C}$. Samples of overnight cultures were transferred to fresh liquid LB media and were grown at $30{ }^{\circ} \mathrm{C}$ until they reached an optical density of 1.0 at $600 \mathrm{~nm}$. Bacterial cultures were centrifuged at $6000 \mathrm{rpm}$ for $10 \mathrm{~min}$ and only supernatants were used for bioassays. Various dilutions of the supernatants were made in water and then $2 \mathrm{ml}$ of each dilutions were pipetted into 24- well plastic plates (Becton Dickinson Labware, Franklin Lakes, NJ). Five Ae. aegypti larvae were transferred into each well with four replications in each treatment. The experiment was repeated five times and the percent mortality in each concentration of the bacterial supernatant was calculated.

MALDI-TOF MS analysis of WT $X$. innexi, $\triangle X I S 1 \_460115$ and $\triangle X I S 1 \_460109$ culture supernatants: $\triangle X I S 1 \_460115, \Delta X I S 1 \_460109$ and WT X. innexi were cultured in liquid LB media for $24 \mathrm{~h}$ at $30{ }^{\circ} \mathrm{C}$, and then centrifuged at $6000 \mathrm{rpm}$ to collect supernatants. Supernatants were submitted for Matrix-assisted laser desorption/ionization time-of-flight mass spectrometry (MALDI-TOF MS) analysis to examine the potential mass profile differences between WT $X$. innexi and mutants (Biotechnology Center, University of WisconsinMadison).

\section{Additional Files}

Additional file 1: Growth rates of $X$. innexi, $X$. nematophila and $X$ bovienii in vitro and in vivo (PDF $77 \mathrm{~kb}$ ) 
Additional file 2: Percent survival over 50 days of $D$. melanogaster flies injected with controls or X. nematophila. (PDF $500 \mathrm{~kb}$ )

Additional file 3: List of $X$. nematophila ATCC19061 genes present in $X$. bovienii SS-2004, X. doucetiae FRM16, but absent in X. innexi HGB1681. (XLSX 42 kb)

Additional file 4: ORFs used for T3SS BLASTp analysis of $X$. innexi draft genome. (PDF $104 \mathrm{~kb}$ )

Additional file 5: Repeat domains in MARTX-like genes of $X$. innexi (PDF $141 \mathrm{~kb}$ )

Additional file 6: Accession numbers of the sequences used in the phylogenetic analyses of TpsA proteins (PDF $85 \mathrm{~kb}$ )

Additional file 7: $X$. innexi loci with genes predicted to encode T6SS components. (PDF $72 \mathrm{~kb}$ )

Additional file 8: A. domesticus infected with S. scapterisci. (PDF $5505 \mathrm{~kb}$ ) Additional file 9: MALDI-TOF MS of WT X. innexi, $\triangle X I S 1 \_460109$ and $\triangle X I S 1$ 460115. (PDF $330 \mathrm{~kb})$

Additional file 10: AntiSMASH analysis of NRPS and PKS genes from XIS1_460105 to XIS1_460116. (ZIP $2696 \mathrm{~kb})$

\section{Abbreviations}

A-: Adenylation-; AA: Amino acid; AntiSMASH: Antibiotics and secondary metabolite analysis shell; AT-: Acyltransferase-; BLAST: Basic local alignment search tool; BLASTp: Protein basic local alignment search tool; CDS: Coding DNA sequence; Cfu: Colony forming unit; CTDs: C-terminal domains; Da: Dalton; DAB: Diaminobutyric acid; DAP: Diaminopimelic acid; DNA: Deoxyribonucleic acid; EPN: Entomopathogenic nematode; GC: Guanine-cytosine; GFP: Green fluorescent protein; HPI: Hours post infection; HPLC/MS: High performance liquid chromatograph/mass spectrometry; IJ: Infective juvenile; LA: Lipid agar; LB: Luria bertani; L-DOPA: L-dihydroxyphenylalanine; MaGe: Magnifying genomes server; MALDI-TOF MS: Matrix assisted laser desorption ionization-time of flight mass spectrometry; MARTX: Multifunctional autoprocessing repeats-in-toxin toxins; Mbp: Megabase pair; Mcf: Makes caterpillars floppy; NBTA: Nutrient bromothymol blue agar; NCBI: National center for biotechnology information; NRPS: Nonribosomal peptide synthetase; $\mathrm{OD}_{600}$ : Optical density at a wavelength of $600 \mathrm{~nm}$; ORF: Open reading frame; PBS: Phosphate buffered saline; PCR: Polymerase chain reaction; PKS: Polyketide synthase; PO: Phenoloxidase; Rpm: Revolutions per minute; rRNA: Ribosomal ribonucleic acid; SD: Standard deviation; T3S: Type III secretion; T5SS: Type V secretion system; T6SS: Type VI secretion system; TA: Toxin-antitoxin; TPP: Threonine phosphorylation pathway; TPS: Two-partner secretion tRNA: Transfer ribonucleic acid; XIt: Xenorhabdus lipoprotein toxin

\section{Acknowledgements}

The authors wish to thank Melinda Hauser and Xiaofei Bai for their assistance with microscopy.

\section{Funding}

Work in the Goodrich-Blair lab was supported by a grant (IOS-1353674) from the National Science Foundation, the UW-Madison United States Department of Agriculture (USDA) Hatch Multi-state research formula fund (WIS01582), and the University of Tennessee-Knoxville. TJM and ÁMCT were supported by a grant from the National Institutes of Health Research Service Award T32-GM07215 and ÁMCT was also supported by an Advance Opportunity Fellowship through the Science and Medicine Graduate Research Scholars Program at UW-Madison. SKA and ARD were supported by a National Institutes of Health K22 award from the National Institute of Allergy and Infectious Diseases (Al119155) awarded to ARD. None of these funding agencies had any role in the design of the study or the collection, analysis, and interpretation of data or in writing the manuscript.

\section{Availability of data and materials}

Accession for the whole genome shotgun sequencing project: FTLG00000000.1. The XIS1 draft genome comprises 69 scaffolds (LT699767LT699835) and 246 contigs (FTLG01000001-FTLG01000246). Additional data supporting the conclusions of this article are included within the article and its additional files.

\section{Authors' contributions}

I-HK carried out mosquitocidal toxin experiments and wrote portions of the manuscript. SKA conducted virulence assays in Drosophila and Galleria, while AMC-T and MPK conducted virulence assays in Manduca. DTA established X. innexi/S. scapterisci rearing mechanisms in crickets and calculated Xenorhabdus colonization levels. EJM and TJM evaluated colonization phenotypes of $X$. innexi in S. scapterisci and TJM also conducted bacterial growth analyses and T3SS comparisons and helped write and edit the manuscript. KH conducted T6SS and Rhs comparisons and phenoloxidase assays. J-CO, and SG conducted comparisons of TPS and helped edit the manuscript. WGG helped supervise I-HK at UW-Madison and edited the manuscript. JCE identified and completed preliminary characterization of the mosquitocidal toxin and acquired funding to obtain the genome sequence. HGB was responsible for supervision of the research at UW-Madison and UTK, acquisition of funding, analysis of TPS, MARTX, and other genomic elements, and writing of the manuscript. ARD was responsible for supervising research at UC Riverside, acquisition of relevant funding, writing the manuscript, and analyzing genomic content. All authors read and approved the final manuscript.

\section{Ethics approval and consent to participate}

Not applicable. This study did not involve human subjects, human material, or human data.

\section{Consent for publication}

Not applicable. This manuscript does not include details, images, or videos relating to individual participants.

\section{Competing interests}

JCE declares pursuit of a patent pertaining to the activity of the mosquitocidal toxin (see bibliography for reference). All other authors declare that they have no competing interests.

\section{Publisher's Note}

Springer Nature remains neutral with regard to jurisdictional claims in published maps and institutional affiliations.

\section{Author details}

${ }^{1}$ Department of Entomology, University of Wisconsin-Madison, Madison, WI, USA. ${ }^{2}$ Present address: Laboratory of Malaria and Vector Research, National Institute of Allergy and Infectious Diseases, Rockville, MD, USA. ${ }^{3}$ Department of Nematology, University of California, Riverside, CA, USA. ${ }^{4}$ Department of Bacteriology, University of Wisconsin-Madison, Madison, WI, USA.

${ }^{5}$ Department of Microbiology, University of Tennessee-Knoxville, Knoxville, TN, USA. ${ }^{6}$ DGIMI, INRA, Université de Montpellier, 34095 Montpellier, France.

Received: 7 June 2017 Accepted: 16 November 2017 Published online: 01 December 2017

\section{References}

1. Herbert EE, Goodrich-Blair H. Friend and foe: the two faces of Xenorhabdus nematophila. Nat Rev Microbiol. 2007;5(8):634-46. doi: 10.1038/nrmicro1706.

2. Kumari P, Mahapatro GK, Banerjee N, Sarin NB. Ectopic expression of GroEL from Xenorhabdus nematophila in tomato enhances resistance against Helicoverpa armigera and salt and thermal stress. Transgenic Res. 2015;24(5): 859-73. doi: 10.1007/s11248-015-9881-9.

3. Zhang $H$, Mao J, Liu F, Zeng F. Expression of a nematode symbiotic bacterium-derived protease inhibitor protein in tobacco enhanced tolerance against Myzus persicae. Plant Cell Rep. 2012;31(11):1981-9. doi: 10.1007/s00299-012-1310-4.

4. Bisch G, Ogier JC, Medigue C, Rouy Z, Vincent S, Tailliez P, et al. Comparative genomics between two Xenorhabdus bovienii strains highlights differential evolutionary scenarios within an entomopathogenic bacterial species. Genome Biol Evol. 2016;8(1):148-60. doi: 10.1093/gbe/evv248.

5. Challinor VL, Bode HB. Bioactive natural products from novel microbial sources. Ann N Y Acad Sci. 2015;1354:82-97. doi: 10.1111/nyas.12954.

6. Chaston JM, Suen G, Tucker SL, Andersen AW, Bhasin A, Bode E, et al. The entomopathogenic bacterial endosymbionts Xenorhabdus and Photorhabdus: convergent lifestyles from divergent genomes. PLoS One. 2011;6(11):e27909. doi: 10.1371/journal.pone.0027909.

7. Ogier JC, Pages S, Bisch G, Chiapello H, Medique C, Rouy Z, et al. Attenuated virulence and genomic reductive evolution in the 
entomopathogenic bacterial symbiont species, Xenorhabdus poinarii. Genome Biol Evol. 2014;6(6):1495-513. doi: 10.1093/gbe/evu119.

8. Nguyen KB, Smart GCJ. Steinernema scapterisci, new species (Rhabditida: Steinernematidae). J Nematol. 1990;22(2):187-99.

9. Nguyen KB. A new nematode parasite of mole crickets: its taxonomy, biology and potential for biological control. [Ph.D.]. Gainesville: University of Florida; 1988.

10. Bonifassi E, Fischer-Le Saux M, Boemare N, Lanois A, Laumond C, Smart G. Gnotobiological study of infective juveniles and symbionts of Steinernema scapterisci: a model to clarify the concept of the natural occurrence of monoxenic associations in entomopathogenic nematodes. J Invertebr Pathol. 1999;74:164-72

11. Lu D, Sepulveda C, Dillman AR. Infective juveniles of the entomopathogenic nematode Steinernema scapterisci are preferentially activated by cricket tissue. PLoS One. 2017;12(1):e0169410. doi: 10.1371/journal.pone.0169410.

12. Lengyel K, Lang E, Fodor A, Szallas E, Schumann P, Stackebrandt E. Description of four novel species of Xenorhabdus, family Enterobacteriaceae: Xenorhabdus budapestensis sp. nov., Xenorhabdus ehlersii sp. nov., Xenorhabdus innexi sp. nov., and Xenorhabdus szentirmaii sp. nov. Syst Appl Microbiol. 2005:28:115-22.

13. Sicard M, Ramone H, Le Brun N, Pages S, Moulia C. Specialization of the entomopathogenic nematode Steinernema scaptersci with its mutualistic Xenorhabdus symbiont. Naturwissenschaften. 2005;92:472-6.

14. Spiridonov SE, Reid AP, Podrucka K, Subbotin SA, Moens M. Phylogenetic relationships within the genus Steinernema (Nematoda: Rhabditida) as inferred from analyses of sequences of the ITS1-5.8S-ITS2 region of rDNA and morphological features. Nematology. 2004;6:547-66.

15. Nadler SA, Bolotin E, Stock SP. Phylogenetic relationships of Steinernema Travassos, 1927 (Nematoda: Cephalobina: Steinernematidae) based on nuclear, mitochondrial and morphological data. Syst Parasitol. 2006;63(3): 161-81. doi: 10.1007/s11230-005-9009-3.

16. Lee MM, Stock SP. A multilocus approach to assessing co-evolutionary relationships between Steinernema spp. (Nematoda: Steinernematidae) and their bacterial symbionts Xenorhabdus spp. (gamma-Proteobacteria: Enterobacteriaceae). Syst Parasitol. 2010;77(1):1-12. doi: 10.1007/s11230-010-9256-9.

17. Dillman AR, Macchietto M, Porter CF, Rogers A, Williams B, Antoshechkin I, et al. Comparative genomics of Steinernema reveals deeply conserved gene regulatory networks. Genome Biol. 2015;16(1):200. doi: 10.1186/s13059-0150746-6.

18. Nguyen KB, Smart GCJ. Pathogenicity of Steinernema scapterisci to selected invertebrates. J Nematol. 1991;23(1):7-11.

19. Wang Y, Gaugler R, Cui L. Variations in immune response of Popillia japonica and Acheta domesticus to Heterorhabditis bacteriophora and Steinernema species. J Nematol. 1994;26(1):11-8.

20. Bonner TP. Changes in the structure of Nippostrongylus brasiliensis intestinal cells during development from the free-living to the parasitic stages. J Parasitol. 1979;65(5):745-50.

21. Hawdon JM, Schad GA. Serum-stimulated feeding in vitro by third-stage infective larvae of the canine hookworm Ancylostoma caninum. J Parasitol. 1990;76(3):394-8.

22. Balasubramanian N, Hao YJ, Toubarro D, Nascimento G, Simoes N. Purification, biochemical and molecular analysis of a chymotrypsin protease with prophenoloxidase suppression activity from the entomopathogenic nematode Steinernema carpocapsae. Int J Parasitol. 2009;39(9):975-84. doi: 10.1016/j.jpara.2009.01.012

23. Toubarro D, Lucena-Robles M, Nascimento G, Costa G, Montiel R, Coelho $A V$, et al. An apoptosis-inducing serine protease secreted by the entomopathogenic nematode Steinernema carpocapsae. Int J Parasitol. 2009: 39(12):1319-30. doi: 10.1016/j.jijpara.2009.04.013.

24. Sicard M, Le Brun N, Pages S, Godelle B, Boemare N, Moulia C. Effect of native Xenorhabdus on the fitness of their Steinernema hosts: contrasting types of interactions. Parasitol Res. 2003;91:520-4.

25. Grewal PS, Matsuura M, Converse V. Mechanisms of specificity of association between the nematode Steinernema scapterisci and its symbiotic bacterium. Parasitology. 1997;114(5):483-8.

26. Mitani DK, Kaya HK, Goodrich-Blair H. Comparative study of the entomopathogenic nematode, Steinernema carpocapsae, reared on mutant and wild-type Xenorhabdus nematophila. Biol Control. 2004;29:382-91.

27. Hussa E, Goodrich-Blair H. Rearing and injection of Manduca sexta larvae to assess bacterial virulence. J Vis Exp. 2012;70:e4295. doi: 10.3791/4295.

28. Ensign JC, Lan Q, Dyer DH, inventors; Mosquitocidal Xenorhabdus, lipopeptide and methods. 2014 US Patent US20140274880 A1.
29. Kim IH, Ensign J, Kim DY, Jung HY, Kim NR, Choi BH, et al. Specificity and putative mode of action of a mosquito larvicidal toxin from the bacterium Xenorhabdus innexi. J Invertebr Pathol. 2017;149:21-8. doi: 10.1016/j.jip.2017. 07.002 .

30. Murfin KE, Chaston J, Goodrich-Blair H. Visualizing bacteria in nematodes using fluorescence microscopy. J Vis Exp. 2012;68:e4298. doi: 10.3791/4298.

31. Veesenmeyer JL, Andersen AW, Lu X, Hussa EA, Murfin KE, Chaston JM, et al. NilD CRISPR RNA contributes to Xenorhabdus nematophila colonization of symbiotic host nematodes. Mol Microbiol. 2014;93(5):1026-42. doi: 10.1111/mmi.12715.

32. Dunphy GB. Interaction of mutants of Xenorhabdus nematophilus (Enterobacteriaceae) with antibacterial systems of Galleria mellonella larvae (Insecta: Pyralidae). Can J Microbiol. 1994;40(3):161-8.

33. Blackburn D, Wood PL Jr, Burk TJ, Crawford B, Wright SM, Adams BJ. Evolution of virulence in Photorhabdus spp., entomopathogenic nematode symbionts. Syst Appl Microbiol. 2016;39(3):173-9. doi: 10.1016/j.syapm.2016. 02.003 .

34. Cerenius L, Söderhäll K. The prophenoloxidase-activating system in invertebrates. Immunol Rev. 2004;198:116-26.

35. Seo S, Lee S, Hong Y, Kim Y. Phospholipase A2 inhibitors synthesized by two entomopathogenic bacteria, Xenorhabdus nematophila and Photorhabdus temperata subsp. temperata. Appl Environ Microbiol. 2012;78(11):3816-23. doi: 10.1128/AEM.00301-12.

36. Song CJ, Seo S, Shrestha S, Kim Y. Bacterial metabolites of an entomopathogenic bacterium, Xenorhabdus nematophila, inhibit a catalytic activity of phenoloxidase of the diamondback moth, Plutella xylostella. J Microbiol Biotechnol. 2011;21(3):317-22.

37. Crawford JM, Portmann C, Zhang X, Roeffaers MB, Clardy J. Small molecule perimeter defense in entomopathogenic bacteria. Proc Natl Acad Sci U S A. 2012;109(27):10821-6. doi: 10.1073/pnas.1201160109.

38. Condon C, Liveris D, Squires C, Schwartz I, Squires CL. rRNA operon multiplicity in Escherichia coli and the physiological implications of $r$ rn inactivation. J Bacteriol. 1995;177(14):4152-6.

39. Asai T, Condon C, Voulgaris J, Zaporojets D, Shen B, Al-Omar M, et al. Construction and initial characterization of Escherichia coli strains with few or no intact chromosomal rRNA operons. J Bacteriol. 1999;181(12):3803-9.

40. Gyorfy Z, Draskovits G, Vernyik V, Blattner FF, Gaal T, Posfai G. Engineered ribosomal RNA operon copy-number variants of $E$. coli reveal the evolutionary trade-offs shaping rRNA operon number. Nucleic Acids Res. 2015;43(3):1783-94. doi: 10.1093/nar/gkv040.

41. Castagnola A, Stock SP. Common virulence factors and tissue targets of entomopathogenic bacteria for biological control of lepidopteran pests. Insects. 2014;5(1):139-66. doi: 10.3390/insects5010139.

42. Vallenet D, Labarre L, Rouy Z, Barbe V, Bocs S, Cruveiller S, et al. MaGe: a microbial genome annotation system supported by synteny results. Nucleic Acids Res. 2006:34(1):53-65. doi: 10.1093/nar/gkj406.

43. Waterfield N, Bowen DJ, Fetherston JD, Perry RD, ffrench-Constant RH. The toxin complex genes of Photorhabdus: a growing gene family. Trends Microbiol. 2001;9:185-91

44. Waterfield N, Dabord PJ, Dowling AJ, Yang G, Hares M. ffrench-Constant RH. The insecticidal toxin makes caterpillars floppy 2 (Mcf2) shows similarity to HrmA, an avirulence protein from a plant pathogen. FEMS Microbiol Lett. 2003;229:265-70.

45. Waterfield N, Kamita SG, Hammock BD, ffrench-Constant R. The Photorhabdus Pir toxins are similar to a developmentally regulated insect protein but show no juvenile hormone esterase activity. FEMS Microbiol Lett. 2005;245:47-52.

46. Vigneux F, Zumbihl R, Jubelin G, Ribeiro C, Poncet J, Baghdiguian S, et al. The $x a x A B$ genes encoding a new apoptotic toxin from the insect pathogen Xenorhabdus nematophila are present in plant and human pathogens. J Biol Chem. 2007:282:9571-80.

47. Gavin HE, Satchell KJ. MARTX toxins as effector delivery platforms. Pathog Dis. 2015;73(9):ftv092. doi: 10.1093/femspd/ftv092.

48. Kim BS, Gavin HE, Satchell KJ. Distinct roles of the repeat-containing regions and effector domains of the Vibrio vulnificus multifunctional-autoprocessing repeats-in-toxin (MARTX) toxin. MBio. 2015;6(2) doi: 10.1128/mBio.00324-15.

49. Antic I, Biancucci M, Zhu Y, Gius DR, Satchell KJ. Site-specific processing of Ras and Rap1 switch I by a MARTX toxin effector domain. Nat Commun. 2015:6:7396. doi: 10.1038/ncomms8396.

50. Biancucci M, Rabideau AE, Lu Z, Loftis AR, Pentelute BL, Satchell KJF. Substrate recognition of MARTX Ras/Rap1-specific Endopeptidase. Biochemist. 2017;56(21):2747-57. doi: 10.1021/acs.biochem.7b00246. 
51. Satchell KJ. Structure and function of MARTX toxins and other large repetitive RTX proteins. Annu Rev Microbiol. 2011;65:71-90. doi: 10.1146/ annurev-micro-090110-102943.

52. Satchell KJ. Multifunctional-autoprocessing repeats-in-toxin (MARTX) toxins of Vibrios. Microbiol Spectr. 2015;3(3) doi: 10.1128/microbiolspec.VE-0002-2014.

53. Jacob-Dubuisson F, Locht $C$, Antoine R. Two-partner secretion in gramnegative bacteria: a thrifty, specific pathway for large virulence proteins. Mol Microbiol. 2001;40(2):306-13.

54. Nikolakakis K, Amber S, Wilbur JS, Diner EJ, Aoki SK, Poole SJ, et al. The toxin/immunity network of Burkholderia pseudomallei contact-dependent growth inhibition (CDI) systems. Mol Microbiol. 2012;84(3):516-29. doi: 10. 1111/j.1365-2958.2012.08039.x.

55. Aoki SK, Poole SJ, Hayes CS, Low DA. Toxin on a stick: modular CDI toxin delivery systems play roles in bacterial competition. Virulence. 2011;2(4):356-9.

56. Aoki SK, Pamma R, Hernday AD, Bickham JE, Braaten BA, Low DA. Contactdependent inhibition of growth in Escherichia coli. Science. 2005;309(5738): 1245-8. doi: 10.1126/science.1115109.

57. Aoki SK, Diner EJ, de Roodenbeke CT, Burgess BR, Poole SJ, Braaten BA, et al. A widespread family of polymorphic contact-dependent toxin delivery systems in bacteria. Nature. 2010;468(7322):439-42. doi: 10.1038/nature09490.

58. Ogier JC, Duvic B, Lanois A, Givaudan A, Gaudriault S. A new member of the growing family of contact-dependent growth inhibition systems in Xenorhabdus doucetiae. PLoS One. 2016;11(12):e0167443. doi: 10.1371/ journal.pone.0167443.

59. Cowles KN, Goodrich-Blair H. Expression and activity of a Xenorhabdus nematophila haemolysin required for full virulence towards Manduca sexta insects. Cell Microbiol. 2005;2:209-19.

60. Brillard J, Ribeiro C, Boemare N, Brehélin M, Givaudan A. Two distinct hemolytic activities in Xenorhabdus nematophila are active against immunocompetent insect cells. Appl Environ Microbiol. 2001;67:2515-25.

61. Ruhe ZC, Low DA, Hayes CS. Bacterial contact-dependent growth inhibition. Trends Microbiol. 2013;21(5):230-7. doi: 10.1016/j.tim.2013.02.003.

62. Ho BT, Dong TG, Mekalanos JJ. A view to a kill: the bacterial type VI secretion system. Cell Host Microbe. 2014;15(1):9-21. doi: 10.1016/j.chom. 2013.11.008

63. Hachani A, Allsopp LP, Oduko Y, Filloux A. The VgrG proteins are "a la carte" delivery systems for bacterial type VI effectors. J Biol Chem. 2014;289(25): 17872-84. doi: 10.1074/jbc.M114.563429.

64. Mougous JD, Gifford CA, Ramsdell TL, Mekalanos JJ. Threonine phosphorylation post-translationally regulates protein secretion in Pseudomonas aeruginosa. Nat Cell Biol. 2007;9(7):797-803. doi: 10.1038/ ncb1605.

65. Cianfanelli FR, Monlezun L, Coulthurst SJ. Aim, load, fire: the type VI secretion system, a bacterial nanoweapon. Trends Microbiol. 2016;24(1):5162. doi: 10.1016/j.tim.2015.10.005

66. Whitney JC, Beck CM, Goo YA, Russell AB, Harding BN, De Leon JA, et al Genetically distinct pathways guide effector export through the type VI secretion system. Mol Microbiol. 2014;92(3):529-42. doi: 10.1111/mmi.12571.

67. Bondage DD, Lin JS, Ma LS, Kuo CH, Lai EM. VgrG C terminus confers the type $\mathrm{VI}$ effector transport specificity and is required for binding with PAAR and adaptor-effector complex. Proc Natl Acad Sci U S A. 2016;113(27): E3931-40. doi: 10.1073/pnas.1600428113.

68. Jackson AP, Thomas GH, Parkhill J, Thomson NR. Evolutionary diversification of an ancient gene family (rhs) through C-terminal displacement. BMC Genomics. 2009:10:584. doi: 10.1186/1471-2164-10-584

69. Alcoforado Diniz J, Liu YC, Coulthurst SJ. Molecular weaponry: diverse effectors delivered by the type VI secretion system. Cell Microbiol. 2015. 17(12):1742-51. doi: 10.1111/cmi.12532.

70. Jamet $A$, Nassif $X$. New players in the toxin field: polymorphic toxin systems in bacteria. MBio. 2015:6(3):e00285-15. doi: 10.1128/mBio.00285-15.

71. Nikolouli K, Mossialos D. Bioactive compounds synthesized by nonribosomal peptide synthetases and type-I polyketide synthases discovered through genome-mining and metagenomics. Biotechnol Lett. 2012;34(8): 1393-403. doi: 10.1007/s10529-012-0919-2

72. Du L, Sánchez C, Shen B. Hybrid peptide-polyketide natural products: biosynthesis and prospects toward engineering novel molecules. Metab Eng. 2001;3(1):78-95

73. Beresky MA, Hall DW. The influence of phenylthiourea on encapsulation, melanization, and survival in larvae of the mosquito Aedes aegypti parasitized by the nematode Neoaplectana carpocapsae. J Invertebr Pathol. 1977;29(1):74-80.
74. da Silva OS, Prado GR, da Silva JL, Silva CE, da Costa M, Heermann R. Oral toxicity of Photorhabdus luminescens and Xenorhabdus nematophila (Enterobacteriaceae) against Aedes aegypti (Diptera: Culicidae). Parasitol Res. 2013:112(8):2891-6. doi: 10.1007/s00436-013-3460-x.

75. Benning MM, Wesenberg G, Liu R, Taylor KL, Dunaway-Mariano D, Holden $\mathrm{HM}$. The three-dimensional structure of 4-hydroxybenzoyl-CoA thioesterase from Pseudomonas sp. strain CBS-3. J Biol Chem. 1998;273(50):33572-9.

76. Wilcke M, Alexson SE. Characterization of acyl-CoA thioesterase activity in isolated rat liver peroxisomes. FEBS J. 1994;222(3):803-11.

77. Svensson LT, Alexson SE, Hiltunen JK. Very long chain and long chain acyl-coA thioesterases in rat liver mitochondria. Identification, purification, characterization and induction by peroxisome proliferators. J Biol Chem. 1995;270(20):12177-83.

78. Hunt MC, Solaas K, Kase BF, Alexson SE. Characterization of an acyl-coA thioesterase that functions as a major regulator of peroxisomal lipid metabolism. J Biol Chem. 2002;277(2):1128-38. doi: 10.1074/jbc.M106458200.

79. Masschelein J, Mattheus W, Gao LJ, Moons P, Van Houdt R, Uytterhoeven B, et al. A PKS/NRPS/FAS hybrid gene cluster from Serratia plymuthica RVH1 encoding the biosynthesis of three broad spectrum, zeamine-related antibiotics. PLoS One. 2013;8(1):e54143. doi: 10.1371/journal.pone.0054143.

80. Fuchs SW, Grundmann F, Kurz M, Kaiser M, Bode HB. Fabclavines: bioactive peptide-polyketide-polyamino hybrids from Xenorhabdus. Chembiochem. 2014;15(4):512-6. doi: 10.1002/cbic.201300802.

81. Pidot SJ, Coyne S, Kloss F, Hertweck C. Antibiotics from neglected bacterial sources. Int J Med Microbiol. 2014;304(1):14-22. doi: 10.1016/j.jjmm.2013.08.011.

82. Bashey F, Hawlena H, Lively CM. Alternative paths to success in a parasite community: within-host competition can favor higher virulence or direct interference. Evolution. 2013;67(3):900-7. doi: 10.1111/j.1558-5646.2012.01825.x.

83. Murfin KE, Lee MM, Klassen JL, McDonald BR, Larget B, Forst S, et al. Xenorhabdus bovienii strain diversity impacts coevolution and symbiotic maintenance with Steinernema spp. nematode hosts. MBio. 2015;6(3): e00076. doi: 10.1128/mBio.00076-15.

84. Tailliez P, Laroui C, Ginibre N, Paule A, Pages S, Boemare N. Phylogeny of Photorhabdus and Xenorhabdus based on universally conserved proteincoding sequences and implications for the taxonomy of these two genera. Proposal of new taxa: $X$. vietnamensis sp. nov., P. luminescens subsp. caribbeanensis subsp. nov., $P$. luminescens subsp. hainanensis subsp. nov., $P$. temperata subsp. khanii subsp. nov., $P$. temperata subsp. tasmaniensis subsp. nov., and the reclassification of $P$. luminescens subsp. thracensis as $P$. temperata subsp. thracensis comb. nov. Int J Syst Evol Microbiol. 2010;60(Pt 8):1921-37. doi: 10.1099/ijs.0.014308-0.

85. Converse V, Grewal PS. Virulence of entomopathogenic nematodes to the western masked chafer Cyclocephala hirta (Coleoptera: Scarabaeidae). J Econ Entomol. 1998;91(2):428-32.

86. Rosa JS, Cabral C, Simoes N. Differences between the pathogenic processes induced by Steinernema and Heterorhabditis (Nemata: Rhabditida) in Psudaletia unipuncta (Insecta: Lepidoptera). J Invertebr Pathol. 2002;80:46-54.

87. Fallon DJ, Solter LF, Bauer LS, Miller DL, Cate JR, McManus ML. Effect of entomopathogenic nematodes on Plectrodera scalator (Fabricius) (Coleoptera: Cerambycidae). J Invertebr Pathol. 2006;92(1):55-7. doi: 10.1016/j.jip.2006.01.006.

88. Bode HB. Entomopathogenic bacteria as a source of secondary metabolites. Curr Opin Chem Biol. 2009;13(2):224-30. doi: 10.1016/j.cbpa.2009.02.037.

89. Boszormenyi E, Ersek T, Fodor A, Fodor AM, Foldes LS, Hevesi M, et al. Isolation and activity of Xenorhabdus antimicrobial compounds against the plant pathogens Erwinia amylovora and Phytophthora nicotianae. J Appl Microbiol. 2009;107(3):746-59. doi: 10.1111/j.1365-2672.2009.04249.x.

90. Fuchs SW, Sachs CC, Kegler C, Nollmann FI, Karas M, Bode HB. Neutral loss fragmentation pattern based screening for arginine-rich natural products in Xenorhabdus and Photorhabdus. Anal Chem. 2012:84(16):6948-55. doi: 10. 1021/ac300372p.

91. Hellberg JE, Matilla MA, Salmond GP. The broad-spectrum antibiotic, zeamine, kills the nematode worm Caenorhabditis elegans. Front Microbiol. 2015:6:137. doi: 10.3389/fmicb.2015.00137.

92. Masschelein J, Clauwers C, Stalmans K, Nuyts K, De Borggraeve W, Briers Y, et al. The zeamine antibiotics affect the integrity of bacterial membranes. Appl Environ Microbiol. 2015;81(3):1139-46. doi: 10.1128/AEM.03146-14.

93. Andreadis TG, Hall DW. Neoaplectana carpocapsae:encapsulation in Aedes aegypti and changes in host hemocytes and hemolymph proteins. Exp Parasitol. 1976:39(2):252-61.

94. Carrillo C, Teruel JA, Aranda FJ, Ortiz A. Molecular mechanism of membrane permeabilization by the peptide antibiotic surfactin. Biochim Biophys Acta. 2003;1611(1-2):91-7. doi: 10.1016/S0005-2736(03)00029-4. 
95. Straus SK, Hancock REW. Mode of action of the new antibiotic for grampositive pathogens daptomycin: comparison with cationic antimicrobial peptides and lipopeptides. Biochim Biophys Acta. 2006;1758(9):1215-23. doi: 10.1016/j.bbamem.2006.02.009.

96. Assie LK, Deleu M, Arnaud L, Paquot M, Thonart P, Gaspar C, et al. Insecticide activity of surfactins and iturins from a biopesticide Bacillus subtilis Cohn (\$499 strain). Meded Rijksuniv Gent Fak Landbouwkd Toegep Biol Wet. 2002;67(3):647-55.

97. Das K, Mukherjee AK. Assessment of mosquito larvicidal potency of cyclic lipopeptides produced by Bacillus subtilis strains. Acta Trop. 2006;97(2):16873. doi: 10.1016/j.actatropica.2005.10.002.

98. Ongena M, Henry G, Thonart P. The Roles of Cyclic Lipopeptides in the Biocontrol Activity of Bacillus subtilis. In: Gisi U, Chet I, Gullino M. (eds) Recent Developments in Management of Plant Diseases. Plant Pathology in the 21st Century (Contributions to the 9th International Congress), Springer, Dordrecht. 2010;1.

99. Singh P, Cameotra SS. Potential applications of microbial surfactants in biomedical sciences. Trends Biotechnol. 2004;22(3):142-6. doi: 10.1016/j. tibtech.2004.01.010.

100. Boemare NE, Akhurst RJ. Biochemical and physiological characterization of colony form variants in Xenorhabdus spp. (Enterobacteriaceae). J Gen Microbiol. 1988;134:751-61.

101. Xu J, Hurlbert RE. Toxicity of irradiated media for Xenorhabdus spp. Appl Environ Microbiol. 1990;56:815-8.

102. Vivas El, Goodrich-Blair H. Xenorhabdus nematophilus as a model for hostbacterium interactions: rpoS is necessary for mutualism with nematodes. J Bacteriol. 2001;183(16):4687-93.

103. Dillman AR, Chaston JM, Adams BJ, Ciche TA, Goodrich-Blair H, Stock SP, et al. An entomopathogenic nematode by any other name. PLoS Path. 2012:8(3):e1002527. doi: 10.1371/journal.ppat.1002527.

104. Krebs K, Lan Q. Isolation and expression of a sterol carrier protein-2 gene from the yellow fever mosquito, Aedes aegypti. Insect Mol Biol. 2003;12(1): 51-60.

105. Pham LN, Dionne MS, Shirasu-Hiza M, Schneider DS. A specific primed immune response in Drosophila is dependent on phagocytes. PLoS Path. 2007;3(3):e26. doi: 10.1371/journal.ppat.0030026.

106. White GFA. Method for obtaining infective nematode larvae from cultures. Science. 1927:66:302-3.

107. Bao Y, Lies DP, Fu H, Roberts GP. An improved Tn7-based system for the single-copy insertion of cloned genes into chromosomes of gram-negative bacteria. Gene. 1991;109:167-8.

108. Teal TK, Lies DP, Wold BJ, Newman DK. Spatiometabolic stratification of Shewanella oneidensis biofilms. Appl Environ Microbiol. 2006;72(11):7324-30. doi: 10.1128/AEM.01163-06.

109. Orchard SS, Goodrich-Blair H. Identification and functional characterization of a Xenorhabdus nematophila oligopeptide permease. Appl Environ Microbiol. 2004;70(9):5621-7.

110. Sambrook J, Fritsch EF, Maniatis T. Molecular cloning: a laboratory manual. 2nd ed. Cold Spring Harbor: Cold Spring Harbor Laboratory Press; 1989.

111. Altschul SF, Madden TL, Schaffer AA, Zhang J, Zhang Z, Miller W, et al. Gapped BLAST and PSI-BLAST: a new generation of protein database search programs. Nucleic Acids Res. 1997;25(17):3389-402.

112. Galtier N, Gouy M, Gautier C. SEAVIEW and PHYLO_WIN: two graphic tools for sequence alignment and molecular phylogeny. Comput Appl Biosci. 1996;12(6):543-8.

113. Castresana J. Selection of conserved blocks from multiple alignments for their use in phylogenetic analysis. Mol Biol Evol. 2000;17(4):540-52.

114. Blin K, Medema MH, Kazempour D, Fischbach MA, Breitling R, Takano E, et al. antiSMASH 2.0-a versatile platform for genome mining of secondary metabolite producers. Nucleic Acids Res. 2013;41(Web Server issue):W20412. doi: $10.1093 /$ nar/gkt449.

115. Röttig M, Medema MH, Blin K, Weber T, Rausch C, Kohlbacher O. NRPSpredictor2 - a web server for predicting NRPS adenylation domain specificity. Nucl Ac Res. 2011;39:W362-7.

116. Zhang Y. I-TASSER server for protein 3D structure prediction. BMC Bioinformat. 2008;9(1):40.

117. Richards GR, Goodrich-Blair H. Examination of Xenorhabdus nematophila lipases in pathogenic and mutualistic host interactions reveals a role for XIPA in nematode progeny production. Appl Environ Microbiol. 2010;76(1): 221-9. doi: 10.1128/AEM.01715-09.
118. Bhasin A, Chaston JM, Goodrich-Blair H. Mutational analyses reveal overall topology and functional regions of NilB, a bacterial outer membrane protein required for host association in a model of animal-microbe mutualism. J Bacteriol. 2012;194(7):1763-76. doi: 10.1128/JB.06711-11.

119. Sugar DR, Murfin KE, Chaston JM, Andersen AW, Richards GR, Deleon L, et al. Phenotypic variation and host interactions of Xenorhabdus bovienii SS2004, the entomopathogenic symbiont of Steinernema jollieti nematodes. Env Microbiol. 2012;14(4):924-39. doi: 10.1111/j.1462-2920.2011.02663.x.

\section{Submit your next manuscript to BioMed Central and we will help you at every step:}

- We accept pre-submission inquiries

- Our selector tool helps you to find the most relevant journal

- We provide round the clock customer support

- Convenient online submission

- Thorough peer review

- Inclusion in PubMed and all major indexing services

- Maximum visibility for your research

Submit your manuscript at www.biomedcentral.com/submit
Biomed Central 